\title{
La Interdicción Aérea a partir de la Experiencia Peruana y la Lucha Contra este Flagelo en Territorio Colombiano ${ }^{8}$
}

\author{
Rodrigo Mezú \\ Eliot Gerardo Benavides
}

\section{Introducción}

El problema mundial de las drogas, como es reconocido por la Organización de las Naciones Unidas (ONU), es una tarea continua que hace parte de la agenda internacional y de la agenda pública de Colombia. Éste es también uno de los aspectos centrales en las relaciones bilaterales de Colombia con los Estados Unidos. Así, a pesar de la lucha contra las drogas diseñada por la administración de Richard Nixon (1969-74) durante los inicios de la década de 1970 , por intermedio de un país tan sui generis como Colombia; este fenómeno transnacional y factor de inestabilidad ha tenido una constante dinámica y evolución frente a las respuestas estatales y multilaterales. Por lo cual, los resultados de esta denominada lucha no son los esperados, pese a los grandes esfuerzos y costos en términos de vidas y recursos destinados para este fin, así

8 Los autores agradecen a cada una de las personas que fueron entrevistadas en el marco de esta investigación y que a partir de su experiencia y conocimiento contribuyeron con esta; entre los cuales, cabe mencionar al Mayor General Henry Quintero, exdirector de Defensa Aérea del país, y a los pilotos peruanos que participaron en el derribo del avión OB-1408. 
como los volúmenes de droga incautada, desarticulación de redes criminales, intervención de bienes y capitales. No obstante, el fenómeno persiste y aparecen nuevos actores que continúan su accionar delictivo.

En un mundo cada día más globalizado e interconectado, algunos programas de lucha contra las drogas se muestran como un éxito en medio de la debacle social que ha ocasionado el comercio ilícito de sustancias psicotrópicas, llámese, marihuana durante la década de 1960, opio durante los setenta o cocaína a partir de los años ochenta. En cualquier caso, esta lucha se ha ido perdiendo (Otis, 2014); y aunque a partir de 2018 los cultivos ilícitos de coca, en Colombia, son aún extensos, los guarismos de la década de 1990, han sido comparados con los de hoy?.

Durante la década de 1980, el narcotráfico era un negocio que se compartía entre los países productores de pasta de coca como Perú y Bolivia, para luego transportarse a Colombia. Sin embargo, a finales de la década de 1990 e inicios del 2000 se presentó una migración total en términos logísticos hacia Colombia (Felbab-Brown, 2005). En otras palabras, con el tiempo todo lo relacionado al procesamiento se empezó a realizar en Colombia, dejando a Perú sin el negocio y a Colombia con todo el proceso de producción y comercialización mayorista (Clutterbuck, 1995). Lo anterior explica el aumento de los cultivos de coca, sumado al constreñimiento de los grupos armados ilegales al campesinado, quienes en ocasiones los obligan a producir coca y, por lo tanto, esta práctica reemplaza a los cultivos lícitos y la producción agrícola.

En este capítulo abordaremos el problema de las drogas y su lucha desde la visión aérea. Esta visión ha tenido un protagonista, la Fuerza Aérea de cada uno de los países, para el caso de los intervinientes, llámese: Colombia, México o Perú. Este último entregó una experiencia no deseada, pero que permitió revisar el procedimiento de interdicción aérea empleado y, así, fortalecer las acciones de control y de toma de decisiones en cuanto al empleo legítimo de la fuerza, hasta ese momento guiados por los Estados Unidos (EE. UU.), que permitieron a Colombia evolucionar a partir de la experiencia peruana.

El caso peruano es de suma importancia en la construcción de una nueva estrategia en la lucha contra el tráfico aéreo de sustancias psicotrópicas. En

9 Según el informe No. 22 de la Oficina de las Naciones Unidas Contra la Droga y el delito UNODC, del total de 42.339 hectáreas de cultivos ilícitos erradicadas de forma voluntaria y asistida, 36.965 hectáreas pertenecían a cultivos ilícitos erradicadas voluntariamente y verificadas por UNODC, sumado a 5.374 hectáreas de cultivos ilícitos con erradicación asistida reportada por la Fuerza Pública en Zonas (PNIS: Programa Nacional Integral de Sustitución de Cultivos Ilícitos). 
efecto, en la década de 1990 y hasta abril de 2001 estuvo vigente un programa antinarcóticos operado bajo la supervisión directa del Gobierno de los EE. UU. por intermedio de la CIA en Colombia y Perú. No obstante, después del derribo en 2001 en territorio peruano del avión OB-1408 con civiles americanos abordo en una operación fallida de interdicción aérea, se canceló el programa. En este sentido, en este capítulo se intentan explicar las razones por la cuales Perú abandona este tipo de operaciones y cómo en Colombia, a partir de lo ocurrido en Perú, se crea una nueva versión del programa en la cual se contemplan protocolos más estrictos en los cuales se enfatiza en los derechos humanos (DDHH). Además, también se explicará cómo la Fuerza Aérea de Colombia (FAC) terminó adelantando el programa de manera autónoma y sin la participación operativa del gobierno estadounidense. Así, la pretensión de este artículo es responder, ¿Bajo cuáles circunstancias operativas funcionaba el Plan de Interdicción Aérea y cuáles fueron los errores que obligaron a una reingeniería del programa a partir del derribo peruano en abril de 2001?

Esta investigación es de tipo cualitativa: se recurrió a fuentes documentales, primarias y secundarias, y se realizaron cuatro entrevistas. En este documento se recogen las versiones de la Agencia Central de Inteligencia de los Estados Unidos (CIA), resultado de la investigación por el derribo de la avión; el testimonio de los pilotos peruanos involucrados en el derribo; la conversación de las tripulaciones que se extrajo del video en YouTube con una duración de 3 minutos 39 segundos, el cual tiene algunas ediciones y no retrata todo el evento de las comunicaciones, y la experiencia de algunas tripulaciones colombianas de defensa aérea que conocieron de cerca el trágico evento y la subsecuente suspensión del programa de interdicción aérea del momento.

La visión que había prevalecido en la lucha contra las drogas llevó a tres países a inicios del siglo XXI: Estados Unidos, Colombia y Perú, a reevaluar su estrategia contra este flagelo luego del doloroso episodio durante 2001 en las inmediaciones de la selva amazónica peruana, el cual al final dejó dos personas muertas y un avión de misioneros estadounidenses derribado (CNN, 2001). A partir de este caso hay un giro en la estrategia tanto en Perú como en Colombia de cómo debía afrontarse el tráfico aéreo ilegal. La experiencia obligó un mayor compromiso por parte de los gobiernos de turno, así como, una mejor preparación técnica de las entidades llamadas a atender el nuevo reto. Entre las cuales cabe destacar a las Fuerzas Militares (FFMM) y, en especial, las Fuerzas Aéreas de Colombia y Perú (Esquivel, 2019). Al final, una 
década después de iniciado el programa de interdicción aérea por los Estados Unidos, solo la primera lograría mantener las exigencias planteadas.

\section{La Lucha Contra el Narcotráfico: Políticas Centradas en la Restricción y Prohibición de la Oferta}

Desde la perspectiva internacional y multilateral el problema de las drogas lleva más de un siglo en la esfera internacional, al igual que su estrategia de lucha contra su aumento (Pardo, 2020). Mientras la evolución en la cadena de producción y comercialización cada día es más innovadora, la estrategia sigue siendo la misma, toda enfocada a la prohibición. Rafael Pardo (2020), político colombiano, resume en una de sus últimas obras esa relación prohibicionista que inicia en el ámbito internacional como se puede ver en la tabla 1.1, pero que también se traduce en normativas dentro de los países firmantes, en un esfuerzo para lograr detener el avance del narcotráfico.

\section{Tabla 1.1}

Relación de Acuerdos o Cumbres asociadas con una estrategia restrictiva y prohibicionista

\begin{tabular}{|c|c|c|c|}
\hline No. & Acuerdo o Cumbre & Detalle & Fecha \\
\hline 1 & $\begin{array}{l}\text { Conferencia de } \\
\text { Shanghái }\end{array}$ & $\begin{array}{l}\text { Contra el Opio: se crea el primer } \\
\text { conjunto de normas para luchar } \\
\text { contra el tráfico de este. }\end{array}$ & $\begin{array}{l}9 \text { de marzo } \\
\text { de } 1909\end{array}$ \\
\hline 2 & $\begin{array}{l}\text { Convención Inter- } \\
\text { nacional del Opio } \\
\text { (La Haya-Holanda) }\end{array}$ & $\begin{array}{l}\text { Primer tratado internacional que } \\
\text { luego haría parte de los compromi- } \\
\text { sos al final de la Gran Guerra. }\end{array}$ & 1912 (1919) \\
\hline 3 & $\begin{array}{l}\text { Nueva Convención } \\
\text { Internacional del } \\
\text { Opio }\end{array}$ & $\begin{array}{l}\text { Se amplía la restricción (aplicación) } \\
\text { a dos sustancias más: la cocaína y el } \\
\text { cannabis. }\end{array}$ & 1925 \\
\hline 4 & $\begin{array}{l}\text { Convención Única } \\
\text { sobre Estupefacientes }\end{array}$ & $\begin{array}{l}\text { Establece un régimen prohibitivo } \\
\text { al uso de las drogas en un listado } \\
\text { referencia. Además, se crea la Junta } \\
\text { Internacional de Fiscalización de } \\
\text { Estupefacientes (JIFE), creada bajo } \\
\text { la sombrilla y con verificación de la } \\
\text { Organización de las Naciones Uni- } \\
\text { das (ONU). }\end{array}$ & 1961 \\
\hline
\end{tabular}




\begin{tabular}{|l|l|l|l|}
\hline No. & Acuerdo o Cumbre & \multicolumn{1}{c|}{ Detalle } & Fecha \\
\hline 5 & $\begin{array}{l}\text { Convención de Vie- } \\
\text { na contra el Tráfico } \\
\text { Ilícito de Estupefa- } \\
\text { cientes y Sustancias } \\
\text { Psicotrópicas }\end{array}$ & $\begin{array}{l}\text { Penalización de las conductas rela- } \\
\text { cionadas con la producción, tráfico } \\
\text { y comercialización de algunas dro- } \\
\text { gas }\end{array}$ & 1988 \\
\hline 6 & $\begin{array}{l}\text { Asamblea Especial de } \\
\text { las Naciones Unidas } \\
\text { (UNGASS) }\end{array}$ & $\begin{array}{l}\text { Creación de mecanismo especial } \\
\text { para el seguimiento y control de } \\
\text { los dineros ilícitos derivados de las } \\
\text { drogas. Se crea la Oficina de las } \\
\text { Naciones Unidas contra la Droga y } \\
\text { el Delito (ONUDD) }\end{array}$ & 1998 \\
\hline 7 & $\begin{array}{l}\text { Nueva Reunión de } \\
\text { UNGASS }\end{array}$ & $\begin{array}{l}\text { Compromiso de abordar y con- } \\
\text { trarrestar eficazmente el problema } \\
\text { mundial de las drogas }\end{array}$ & 2016 \\
\hline
\end{tabular}

Nota: Elaboración propia basado en Pardo (2020).

Durante el foro internacional "Renovando el Compromiso de Combatir el Narcotráfico”, desarrollado en Bogotá (Colombia) a finales de 2019 Margarita Cabello, la entonces Ministra de Justicia colombiana, aseguraba que, para el 31 de diciembre de 2018, según el informe Sistema Integrado de Monitoreo de Cultivos Ilícitos (SIMCI), se había logrado reducir en $1.4 \%$ el área con cultivos ilícitos en el país. Según Cabello (2019), en tan solo cuatro meses se había detenido la curva ascendente que estaba registrando los cultivos ilícitos desde el 2013. Adicionalmente, en los diez meses de ese año la erradicación de cultivos ilícitos se había incrementado en un 53\% respecto al mismo periodo del año anterior y sumado a ello, se había incrementado la productividad en el número de hectáreas erradicadas lo cual había significado un ritmo de erradicación muchísimo más alto en comparación con las cifras de 2018. Aunque estos resultados animan a las entidades involucradas en la lucha contra el tráfico ilegal de sustancias psicoactivas, también es cierto que cuando se observan las cifras históricas, durante la última década se presentó un aumento en los cultivos de coca en el país. Entre tanto, la exportación de cocaína a los países consumidores en Norte América y Europa por defecto ha ido aumentando. Al respecto, el Mayor General Henry Quintero, exdirector de Defensa Aérea del país, considera que existen tres las razones para este fenómeno se mantenga aún revitalizado: I) la erradicación voluntaria estimuló 
el crecimiento de los cultivos ilegales de coca; II) el proceso de paz ayudó a atomizar algunos grupos al margen de la ley, lo que según dio pie a un "caldo de cultivo" con el aumento de las plantaciones de coca, y III) decisiones políticas, en torno a este gobierno y a lo largo de los años (Entrevista semiestructurada, octubre de 2020).

Las propuestas sobre la lucha contra las drogas se han derivado desde afuera hacia dentro (Bedoya, 2016). Desde espacios dominados por el hegemónico, como Estados Unidos; y desde una esfera restrictiva y prohibitiva que solo requiere una sola respuesta por intermedio del uso de la fuerza. Así, es necesario analizar no solo los resultados que esta política de restricciones ha generado en países productores como Colombia y Perú, pasando por los países de tránsito como México y llegando a los grandes consumidores donde no se persiguen los capos, no hay políticas de extinción de dominio como es el caso de los EE. UU., uno de los mayores consumidores de droga después de Australia y Albania según el World Drug Report (2018). En este sentido, surge la necesidad de analizar una de las acciones y respuestas tendientes a prevenir, desviar, interrumpir o neutralizar el tráfico ilícito de sustancias psicotrópicas desde las zonas de producción hasta los complejos geográficos y políticos donde tiene lugar la demanda que emplean métodos multimodales de transporte entre ellos el medio aéreo y que implica el cruce de límites políticos y el espacio soberano de dos o más Estados.

Se establece como vuelo ilícito aquel que mediante el empleo de una aeronave se realiza el transporte aéreo de sustancias psicotrópicas con esta clara y planeada intención de cometer una actividad indebida, dado el grado de preparación y el grado de trabajo especializado para lograr el cometido. Para ello es necesario vulnerar de manera intencional la soberanía de uno o varios Estados (su territorio), desconocer la aplicación de las normas de navegación establecidas por la Organización de Aviación Civil Internacional (OACI). Además, el desarrollo de estos vuelos ilícitos afecta la seguridad aérea y la operación de otras aeronaves civiles y sus ocupantes, en razón a que violan las normas de tránsito aéreo, entre ellas la presentación de un plan de vuelo ante la autoridad aeronáutica (ATC) y omiten medios activos de identificación, entre ellos el código transpondedor y omiten comunicación efectiva con el ATC. El vuelo ilícito tiene el propósito de transportar la droga desde las zonas de producción hasta los lugares de comercialización o, por lo menos, acercarse a las fronteras de otros países para luego continuar su tráfico ilegal a través de otro medio de transporte. Así, este tipo de vuelos permiten obtener beneficios económicos ilegales y estimulan otro tipo de actividades o delitos conexos. 


\section{La Dinámica de los Vuelos Ilícitos y su Beneficio para las Redes Criminales}

Para una organización criminal constituye de gran valor la eficiencia y los mecanismos para hacer llegar su producción ilícita de sustancias psicotrópicas a manos de los consumidores quienes demandan y pagan un alto valor por obtener este elemento de consumo. En el mismo sentido, las organizaciones criminales desarrollan la logística para cumplir con su objetivo, la logística tal como sucede con las actividades legales requiere de personal, suministro de insumos y precursores. También requieren de medios de transporte multimodal, dado que deben cubrir grandes distancias y desplazarse en medio de condiciones geográficas y utilizar medios terrestres, fluviales y marítimos, con las limitaciones que imponen las acciones de los Estados para la interdicción sobre este transporte ilícito. En este sentido, se justifica transportar por medio aéreo, para alcanzar los puntos y distancias deseadas, a bajo costo y en tiempos reducidos con trayectos de cuatro o cinco horas de vuelo. Existen condiciones que habilitan esta actividad ilícita, en cuanto la disponibilidad de pilotos y aeronaves, deficientes controles internacionales sobre estas actividades de vuelo, la facilidad para preparar el terreno y emplearlas como pistas de aterrizaje y la respuesta estatal que requiere medios de detección, medios aéreos dispuestos y disponibles para la operación (Fuerza Aérea), así como la voluntad política para emplearlos y una estrecha coordinación interinstitucional. Por lo tanto, son cuantiosos los recursos económicos y materiales requeridos para cumplir esta misión de soberanía; sin embargo, no todos los Estados tienen la capacidad, o difícilmente la mantienen, para realizar un control permanente como ocurre en países de Centroamérica, de ahí la importancia de la cooperación entre las fuerzas aéreas de los diferentes países.

También, subsisten riesgos de corrupción para encubrir los vuelos ilícitos; por ejemplo, evitando o disminuyendo su detección en vuelo, cubriendo un espacio aéreo soberano o inclusive afectando el tiempo de reacción una vez son detectados. El factor tiempo es fundamental para que una fuerza aérea pueda actuar, dado que, no es posible mantener en vuelo las aeronaves dispuestas para procesos de interdicción aérea todo el tiempo y, por ende, se disminuye el alcance geográfico. Lo anterior quedó demostrado, aunque en un contexto diferente, en los EE. UU., el Estado con las mayores capacidades aéreas y espaciales, durante los sucesos del 9/11 en los cuales aeronaves civiles fueron empleadas con fines ilícitos. 
Dados los rendimientos financieros obtenidos por las organizaciones al margen de la ley dedicadas al tráfico ilícito de sustancias psicotrópicas, en particular, el lucro obtenido con el transporte de estos elementos de consumo por vía aérea. Se hace necesario que los Estados ejerzan su soberanía en las dimensiones terrestres, marítimas y aéreas; donde se desarrollan rutas y actividades ilícitas. También es importante tomar en cuenta el costo de oportunidad que se obtiene empleando vuelos ilícitos.

\section{Caso de Estudio: El Derribo Peruano que Cambió la His- toria de la Interdicción Aérea en Colombia}

A continuación, se exponen los actores, hechos (génesis y su evolución) y factores frente al derribo de la aeronave OB-1408 inicialmente considerada como sospechosa de estar traficando sustancias ilícitas y, posteriormente, identificada como un vuelo lícito, con lo cual se marcaría un antes y un después en los procesos de interdicción en la región. En su momento, la revisión de la cadena de hechos que condujeron al derribo de la aeronave permitió formular e implementar acciones y normas tendientes a fortalecer las operaciones legítimas de fuerza como último recurso. Adicionalmente, se tomaron medidas preventivas, que fueron ampliamente difundidas dentro de la comunidad aeronáutica y de aviación civil, y se mejoraron los procedimientos radiotelefónicos para facilitar el contacto e interacción de aeronaves civiles y militares en vuelo cuando sucede una interdicción aérea. Dos décadas después del derribo de la aeronave de misioneros, no se han presentado casos similares, con lo cual, pareciera que las medidas tomadas han sido efectivas.

\section{El Contexto Político del Momento}

Para inicios de la década de 1990, el gobierno de los EE. UU. creó un programa con el Perú que replicaría casi al instante con Colombia. Este programa estaba encaminado a luchar contra el tráfico aéreo ilegal de sustancias psicotrópicas y la idea de éste era impedir el puente aéreo entre países productores de droga con los consumidores, en este caso, contra el narcotráfico entre el sur y el norte (Huskisson, 2004). La intención estratégica del programa consistía en reducir las cantidades de droga disponibles en territorio estadounidense y, en un juego de oferta y demanda, aumentar el precio de la droga en las calles a niveles que sobrepasarían la capacidad adquisitiva de 
los consumidores. En resumen, la estrategia consistía en subir el precio para disuadir el consumo en ciudadanos estadounidenses.

El programa, entonces, buscaba la ampliación de la lucha contra el tráfico aéreo con la participación de recursos militares y se encaminaba a reducir este flagelo entre Perú y Colombia, grandes productores de hoja de coca. Por el lado peruano existía una preminencia de producción de pasta de coca, mientras, por el lado colombiano se concentraban en procesar la pasta de coca traída desde el sur para producir clorhidrato de cocaína. Perú durante la década de 1990 era el mayor exportador de pasta de coca a los EE. UU.; pero, rápidamente Colombia de manos de los narcotraficantes y de una red logística ilegal muy coordinada y controlada por los carteles de la droga se fue haciendo con "el negocio". Lo expresaba McCaffrey, zar antidrogas del gobierno estadounidense, en su visita a Bogotá en 1997, donde aseguraba que Perú era dueño del $60 \%$ de la producción de pasta de coca y, a su vez, Colombia estaba creciendo a grandes pasos en esta materia, lo que obligaba a los países vecinos a unir esfuerzos contra este flagelo (LADB Staff, 1997).

Este programa estaba encaminado en perseguir aquellas aeronaves con baja velocidad, mono motores y bimotores, acondicionadas con mucho combustible para hacer largos viajes desde estos países hasta Centroamérica e inclusive proximidades con los Estados Unidos. En su momento, el 90\% de la droga que fluía entre Perú y Colombia se movía por vía aérea. Para finales de la década de 1990, el programa había sido catalogado por algunas personas como un éxito en la "guerra contra las drogas", a pesar de la renuencia de algunos políticos estadounidenses de utilizar la fuerza para derribar aeronaves civiles.

Ha existido una presencia constante de los EE. UU. en Latinoamérica con relación a la lucha contra las drogas a partir del último período presidencial de Ronald Reagan (1981-89). En 1985, los EE. UU. empiezan a subvencionar las operaciones de antinarcóticos en Perú bajo el nombre de Operación Cóndor, la cual tenía como objetivo destruir el puente aéreo de la droga en la región. Con Cóndor los estadounidenses empezaron a incrementar el apoyo logístico y de inteligencia y, con ello, se presentó un aumento de la presencia de tropas estadounidenses es estos países (esta última parte inicia bajo la presidencia de George W. Bush en 1989 bajo el nombre de la Iniciativa de los Andes). Esta iniciativa involucró el despliegue de equipo de fuerzas especiales y el asesoramiento por parte de expertos militares en Bolivia, Colombia y Perú. Para 1990, el Comando Sur de Estados Unidos empieza a proveer más información a estos países con la participación de sistemas de vigilancia radar 
y la asistencia de aeronaves tipo P3 y AWACS equipados para la vigilancia aérea (Helgerson, 2008).

Con la llegada del presidente Bill Clinton (1993-2001) a La Casa Blanca se asentó la presión política de este país hacia mayores resultados. En consecuencia, en 1993 el gobierno peruano implementó el Decreto Ley 25426 denominado también como la "Ley de lucha contra el tráfico ilícito de drogas", por la cual se autorizaba al gobierno a través de la Fuerza Aérea, por primera vez en su historia, a interceptar e incluso usar la fuerza contra aeronaves sospechosas de tráfico ilícito de drogas (artículo 7, Ley 25426, 1993). Entretanto, en Colombia se reúne el Consejo Nacional de Estupefacientes (CNE) y bajo un acta reservada y firmada en diciembre de 1993 se autorizó el derribo de aeronaves al servicio del narcotráfico (Huskisson, 2004, p. 9). El programa funcionaba a la par en Colombia; sin embargo, para el estudio en particular hablaremos de las características y condiciones del programa peruano, que al final, era similar al de su vecino amazónico. Pocas diferencias, una de ellas, su recurso humano.

Una de las condiciones para sospechar de una aeronave al servicio del narcotráfico era su condición de estar volando rutas poco frecuentes, por debajo de los diez mil pies de altura, a velocidades bajas y con planes de vuelo no reportados. Dichas condiciones aplicarían, en su momento, para Colombia y Perú. Después, Colombia empezó a instaurar otro tipo de estrategias para hacer seguimiento a este tipo de aeronaves sospechosas, entre ellas el seguimiento y análisis que involucraba a la infraestructura aeronáutica, no solo aeronaves sospechosas, sino también pilotos, empresas, pistas, aeropuertos y rutas, entre otros (Gagne, 2015).

El programa de negación del puente aéreo peruano recibió, así como en el caso colombiano, recursos y entrenamiento por parte de los Estados Unidos. Se trataba de aeronaves tipo tracker o rastreadores con un radar de adquisición que proveería asistencia a las aeronaves interceptoras que, en todo caso, serían operadas por nacionales peruanos o colombianos a cargo de la Fuerza Aérea de cada país. Asimismo, se aseguraba una comunicación expedita entre aeronaves involucradas en el proceso y los entes de administración aeronáutica, como torres de control (Anthony, Crane \& Hanson, 2000).

En Perú, la CIA se involucró en este programa a partir de 1991 con la entrega de un avión tracker o rastreador. Esta colaboración se extendió hasta 1994 cuando el programa se detiene, ya que, para ese momento los estadounidenses involucrados en estas operaciones no tenían la suficiente protección legal que pudiera mantenerlos al margen de una querella legal a razón de un 
mal procedimiento en el desarrollo de una operación de interdicción a una aeronave ilegal en este territorio. El Departamento de Justicia (DOJ) de los EE. UU. prendería las alarmas, y solo hasta haber brindado la protección suficiente a sus nacionales el programa continuaría. La Fuerza Aérea del Perú (FAP) no podía desarrollar autónomamente el programa, pues la información de posibles aeronaves ilegales volando sobre su territorio era provista desde tierra por los sistemas de información norteamericanos y, en tal sentido, el programa debió suspenderse (Helgerson, 2008).

En mayo de 1994, el DOJ emitió una opinión formal de que el personal de los Estados Unidos que brindó asistencia o información utilizada por la FAP para derribar o destruir un avión civil podría ser penalmente responsable bajo la ley de los Estados Unidos. Como resultado, el apoyo estadounidense a la prohibición peruana de vuelos de drogas se detuvo temporalmente. (Helgerson, 2008, p. 2)

Ese mismo año, el Congreso estadounidense gestionó y otorgó la inmunidad a los funcionarios de su gobierno relacionados con el proceso de interdicción aérea en Perú. En consecuencia, el presidente Bill Clinton renovó el programa estableciendo nuevas estrategias y arreglos en busca de una operación más segura. En marzo de 1995 el programa bilateral se reanudó y estuvo vigente hasta el 20 de abril de 2001, durante este tiempo ambas naciones, según el reporte de la CIA, derribaron 15 aeronaves civiles en territorio peruano (Helgerson, 2008). No obstante, las tripulaciones peruanas entrevistadas aseguran haber derribado, es ese mismo período, más de 100 aeronaves (Entrevista semiestructurada, noviembre de 2020).

El 20 de abril de 2001, en el marco de una operación de interdicción aérea, la FAP derribó la aeronave Cessna A 185E con matrícula OB-1408 en territorio peruano, avión que llevaba a civiles norteamericanos abordo. Este evento causó que se detuviera el programa de interdicción en dicho país y también en Colombia. La experiencia derivada de este doloroso evento se constituyó en una pieza esencial para realizar la reingeniería del programa por parte de los países intervinientes. Lo anterior en aras de proteger la vida de quienes estaban abordo de las aeronaves sospechosas de estar involucrados con el tráfico de narcóticos, así como, las tripulaciones involucradas en la seguridad y soberanía de los países de la región encargadas del proceso de seguimiento, identificación y, llegado el momento, derribo de los posibles ilegales. 


\section{El Estudio de Caso}

El día 20 de abril de 2001 en las horas de la mañana, el sistema de alerta temprana peruano en colaboración con recursos estadounidenses detectó un avión tipo Cessna, C-185, monomotor volando sobre la selva amazónica y con capacidad para acuatizar (ver capítulo dos). Los reportes que llegan a la Fuerza Aérea del Perú informan de una aeronave cruzando sin autorización espacio aéreo nacional desde Brasil. De inmediato se activa el procedimiento de interdicción entre Perú y los Estados Unidos.

La aeronave es interceptada, inicialmente por un avión C-550 "citation" piloteado por funcionarios estadounidenses con un tripulante peruano a bordo, las comunicaciones inicialmente se dan entre miembros de la tripulación mixta, con alguna dificultad por las deficiencias en el idioma: los estadounidenses no dominaban el español, ni los peruanos el idioma inglés. Posteriormente, se une a esta operación un avión de caza interceptor, piloteado por funcionarios peruanos, un A-37B, comúnmente apodado como dragón o alfa; sin embargo, su código de llamado aeronáutico era Tucán (ABC News, 2010).

La aeronave es detectada volando a baja altura, aproximadamente cuatro mil pies sobre el río Amazonas con rumbo, al parecer, hacia Iquitos. Esta inicialmente se reporta como si hubiera ingresado a espacio aéreo peruano desde un lugar indeterminado en Brasil; pero, posterior a la catástrofe, se determina que despegó desde un punto en cercanías a la población de Islandia (Perú) y muy cerca de Benjamín Constant (Brasil) [INL, 2001]. Cabe aclarar que, las dos localidades se encuentran dentro de lo que se conoce como la triple frontera (Colombia-Perú-Brasil). El hidroavión piloteado por Kevin Donaldson llevaba a bordo a la familia Bowers, compuesta por cuatro miembros y quienes el día anterior viajaron a Leticia (Colombia) para solicitar en el consulado peruano una visa de residencia para la menor de sus integrantes, Charity de siete meses (CNN, 2001). Las comunicaciones iniciales, al momento de la detección de la aeronave proceden de la siguiente forma, entre el piloto estadounidense al mando del C-550, el piloto del A-37B y, esporádicamente, el piloto del C-185 (avión derribado) [ABC News, 2010]:

- Piloto estadounidense: I don't know if this is bandido or amigo.

- Piloto peruano (A-37B): ok

- Piloto estadounidense: Is possible we could hit the land in Iquitos, and check? 
- Piloto peruano: ok

- Piloto estadounidense: ok, before ra-ta-ta-ta-ta, ok?

- Piloto peruano: así es, yes yes yes, very well

Pasmosamente, las tripulaciones peruanas y estadounidenses se confundían entre sí por sus deficiencias en los idiomas no dominantes. Mientras el piloto estadounidense dudaba de la condición de avión sospechoso interceptado, el peruano pretendía entender esas dudas. La primera intención del avión de seguimiento era verificar su legalidad en tierra llevando esta aeronave a Iquitos, la ciudad peruana más grande en el Amazonas. Luego la respuesta del piloto interceptor peruano fue un asentimiento; sin embargo, la operación continuaba. En tal sentido, nuevamente aparece la reiteración de los estadounidenses y esta vez mas gráfica, simulando con su voz el ametrallamiento. En ningún caso la operación se detuvo, el piloto peruano respondió con un: "así es, yes yes yes, very well”. Cada cual parecía estar entendiendo a su par, pero según como los eventos se desencadenaron no era así.

Durante la fase uno (fase de comunicaciones con el avión sospechoso), la tripulación peruana hace llamados a la aeronave sospechosa: "aeronave no identificada, usted ha sido interceptada por aviones de la Fuerza Aérea, vire inmediatamente a rumbo 270. De no obedecer procederemos a derribarla” (ABC News, 2010). No obstante, dado que el piloto Donaldson durante el momento no monitoreó ninguna frecuencia VHF no hubo respuesta por parte de esta aeronave (ver capítulo dos). Aunado a lo anterior, los movimientos realizados por el hidroavión fueron considerados como evasivos, por lo cual se autorizó la siguiente fase. La posterior investigación de la CIA, después de haber entrevistado a más de 200 funcionarios peruanos y estadounidenses, concluyó que las condiciones meteorológicas obligaban a la aeronave a volar evitando las nubes, de allí los movimientos erróneamente interpretados como evasivos (2008).

La fase dos compromete al piloto del interceptor a realizar unos disparos denominados como disuasivos al lado izquierdo de la aeronave sospechosa (lado del piloto en los aviones, para los helicópteros su piloto se encuentra a la derecha y por tanto será el lado del interceptor). La intención es lograr la atención del piloto del avión sospechoso y su tripulación. En tal sentido, el avión interceptor debe ponerse al lado de la aeronave sospechosa y hacer los disparos en paralelo a la trayectoria del interceptado, de tal manera que tanto el sonido como los disparos puedan advertir al piloto la condición en la cual 
se encuentra. Al terminar la fase de advertencia o fase dos, las comunicaciones entre estadounidenses y peruanos se hacen más tensas (ABC News, 2010):

- Piloto estadounidense: Are you sure it is bandido?

- Tripulante peruano: Yes, autorizado fase 3.

- Piloto estadounidense: ok, if you are sure

En ese momento la tripulación estadounidense demuestra, entre ellos, su inseguridad sobre el procedimiento. Como se puede escuchar en el video de la operación grabado por la CIA, que fue obtenido y publicado por ABC News en 2010, la conversación queda grabada, pero no elevaron su inconformismo enfáticamente a sus pares peruanos:

- Piloto estadounidense: This guy does not fit the profile

- Copiloto estadounidense: I think they are making a mistake

- Piloto estadounidense: I agree with you

Durante esos instantes, el piloto del hidroavión (aeronave sospechosa) se comunicó con la torre de control de Iquitos (ABC News, 2010):

- Piloto hidroavión (sospechoso): [...] a cuatro mil pies, los militares están acá, no se que quieren... aproximadamente a 35 millas de Iquitos

- Piloto estadounidense: The plane is talking to Iquitos tower

- Piloto hidroavión (sospechoso): ¡NOS ESTAN MATANDO, NOS ESTÁN MATANDO!

- Piloto estadounidense: TELL THEM TO TERMINATE

- Copiloto estadounidense: don't shoot, ¡NO MÁS!

- Tripulate peruano: No más, Tucán, ¡no más!

- Piloto estadounidense: God!

- Piloto peruano (A-37B): ya terminamos, está saliendo humo

El avión interceptado, acuatiza con algunas dificultades sobre el río Amazonas. La revisión por parte de las autoridades peruanas, en tierra, determina que éste no llevaba sustancias ilícitas, ni estaba al servicio del narcotráfico ni bajo procedimientos ilegales. El avión piloteado por el estadounidense, Kevin Donaldson llevaba a bordo a una familia de misioneros del mismo país. Durante el acuatizaje, el avión se voltea y es socorrido por los moradores del 
sector. Durante el proceso de los disparos en el aire por parte de la Fuerza Aérea del Perú un proyectil impacta a Verónica de 35 años y a Charity de siete meses, causándoles la muerte al instante. Los dos integrantes adicionales de la familia Bowers, Jim y Cory de 7 años, padre e hijo salen ilesos. El piloto del hidroavión es herido en una de sus piernas (CNN, 2001).

De las primeras reacciones políticas sobre este penoso acontecimiento estuvo la de La Casa Blanca que, sin hacer alusión al gobierno peruano, se refirió a la responsabilidad de la FAP en el desencadenamiento de los sucesos ese 20 de abril de 2001 en territorio de ese país (CNN, 2001), al no haber seguido los procedimientos establecidos antes de abrir fuego a una aeronave en vuelo. Por su parte, la FAP negó haberse apartado de las reglas de enfrentamiento estandarizadas para este tipo de operaciones. Para David Ensor, reportero del canal de noticias CNN, el error que determinó el derribo del C-185 involucró una mala identificación de la aeronave en vuelo (2001).

\section{El Análisis de los Hechos a partir de los Documentos Estadounidenses}

A raíz de los eventos descritos anteriormente, la División Criminal del Departamento de Justicia del gobierno de los Estados Unidos solicitó a su oficina de Inspección General una investigación exhaustiva sobre el rol y el papel desempeñado por la CIA en la operación y conducción del programa de interdicción, a partir de 1995 hasta 2001. Esta oficina de inspección (OI) hizo una revisión documental de cada uno de los derribos acontecidos en ese lapso, que involucró a 15 operaciones de este tipo en territorio peruano en conjunto con los Estados Unidos. Así, se alcanzaron a reunir más de 200 entrevistas a todos los involucrados y participantes, entre ellos, miembros de la CIA, funcionarios de la FAP, su línea de mando y todas las personas conocedoras del programa entre los países intervinientes.

En sus conclusiones preliminares la OI aseguró observar repetidas violaciones a los procedimientos para identificar, interceptar y posteriormente aplicar la fuerza. En todos estos procedimientos estuvo involucrada la CIA. Según el informe antes mencionado, "a lo largo de la vida del programa hubo evidencia de desviaciones de los procedimientos requeridos, tanto en las cintas de video de los derribos como en los cables de informes a la CIA" (Helgerson, 2008). En todos los casos (1995-2001), según el análisis arrojado por la OI, los aviones sospechosos fueron derribados en contados minutos después 
de la interceptación de los aviones caza peruanos, no mediaba procedimiento de identificación, tampoco advertencias de su parte y sin tiempo para que la aeronave interceptada pudiera responder a estas comunicaciones (2008).

John L. Helgerson (2008), quien desempeñaba la función de inspector en el marco de dicha investigación, hizo un reporte sumarial acerca de los errores incurridos durante el derribo del avión con los misioneros a bordo. Los errores recurrentes no solo en este derribo sino en la gran mayoría de las 15 operaciones se resumen de la siguiente manera: Primero, la no identificación de las aeronaves derribadas de forma eficiente. Esto sucedió en ocho de las 15 interceptaciones realizadas entre peruanos y estadounidenses desde el mismo inicio del programa de interdicción. Segundo, no haber realizado señales visuales capaces de ser observadas por los pilotos de los aviones sospechosos derribados. Este error fue recurrente en todas las interceptaciones realizadas. Tercero, no haber realizado disparos de advertencia. Esta violación se produjo según el informe en al menos ocho interceptaciones. Cuarto, ausencia en la cadena de mando durante el proceso de las interceptaciones. Lo anterior aconteció en 13 de todos los derribos desarrollados. Quinto, falta de tiempo suficiente para que la aeronave interceptada respondiera a las comunicaciones y procedimientos. En la mitad de los derribos pasaron dos minutos entre la primera advertencia y la autorización para la fase final de derribo.

La gran mayoría de los funcionarios estadounidenses, sobre el derribo del avión misionero, aseguraron que gran parte de estos procedimientos sucedieron en horas de la noche. Lo anterior no permitía la observación de las señales visuales y, por tanto, éstas no eran recomendable hacerlas en las horas de la noche. En alguna forma se encuentra contraposición entre la postura de los funcionarios estadounidenses con la realidad, ya que, del total de las interceptaciones 11 sucedieron durante el día y las cuatro restantes en la noche o durante el anochecer. Sumado a ello, y un mes después del derribo del avión misionero, las autoridades peruanas, durante una investigación interna de los sucesos, encontraron inobservancia en los procedimientos de interceptación por parte de sus funcionarios. Al final, sobre estos hallazgos, en cabeza de la oficina jurídica de la Fuerza de Tarea del Perú, nunca quisieron hacer oficial los resultados de estas investigaciones (Helgerson, 2008). Una de las mayores complejidades de esta investigación fue la ausencia de claridad por parte de los funcionarios conocedores y participantes del programa de interdicción tanto de Perú como en los Estados Unidos. Su postura fue siempre reactiva y poco colaborativa, lo que resultó en pocas evidencias en el proceso de la investigación (2008). 
En el informe final adelantado por la OI se le recomienda una reprimenda (carta formal con un regaño) a los funcionarios de la CIA involucrados en la operación (2008):

\begin{abstract}
El gobierno de los Estados Unidos pagó \$8 millones a las víctimas en base a la afirmación de la CIA de que el derribo de los misioneros había sido una aberración en un programa que de otra manera habría cumplido con los procedimientos prescritos por la Presidencia. (Helgerson, 2008)
\end{abstract}

Un oficial de operaciones de alto nivel asignado a la tarea de llevar a cabo una revisión de responsabilidad interna tampoco pudo documentar el grado de incumplimiento que existía en el programa. A pesar de haber tenido acceso al trabajo en curso de la Fuerza de Tarea de Perú y de haber sido informado de sus hallazgos, no tomó nota de estos problemas en su informe final a la alta gerencia de la Agencia.

\title{
La investigación
}

En el proceso de la investigación se realizaron 210 entrevistas y un acumulado de documentos indexados que llegaron a 250 mil páginas, aproximadamente (2008, p. 12). En este trabajo se interrogaron a funcionarios de la CIA, de la Administración para el Control de las Drogas (DEA, por sus siglas en inglés), funcionarios de la Aduana del mismo país, así como, miembros del Consejo de Seguridad Nacional, del Ejercito de los Estados Unidos; también se requirió a funcionarios de los ministerios de Defensa, Justicia, Asuntos Exteriores, FAP y todo el personal involucrado en el proceso de derribo en el Perú:

En total, se entrevistó a 24 oficiales de la Fuerza Aérea del Perú, incluidos cinco de los seis generales al mando, así como pilotos, copilotos y funcionarios involucrados en la verificación de procedimientos de los estadounidenses al interior de Perú quienes volaban como tripulantes de la nación anfitriona (HNR, por sus siglas en inglés) disponibles de la FAP. (Helgerson, 2008)

El programa de interdicción aérea peruano era similar al operado en Colombia, aunque con diferencias en el uso de los procedimientos al aplicar como último recurso la fuerza. Los compromisos entre los países involucrados eran los mismos y el único factor diferencial era el personal del país anfitrión que operaba el programa en conjunto con los Estados Unidos. Las leyes de Perú sobre el derribo estaban enfocadas a cualquier aeronave civil 
que volara durante el día por debajo de diez mil pies de altura, en zonas de poca frecuencia de tráfico aéreo, que despegara desde o hacia aeródromos no controlados por autoridades aeronáuticas y que no reportara ni entregara un plan de vuelo a la autoridad competente. Todo lo anterior se agravaría si la aeronave volaba bajo las condiciones anteriores y durante la noche.

El procedimiento de interceptación peruano se realizaba con dos tipos de aeronaves; el T-27A (Tucano) un turbopropulsor y monomotor construido por la Fabrica Brasilera Aeronáutica (Embraer); así como, el A-37B Dragonfly (A-37) un jet bimotor construido por la Corporación Cessna. Los aviones tipo tracker o rastreadores eran C-550 y eran operados por la CIA. Estas aeronaves eran un híbrido entre avión ejecutivo de alta velocidad y sistemas de fotografía tipo flir, radar de adquisición, similar a aquellos diseñados para aviones de combate tipo F-16 y un sistema integrador de información geográfica. Era un avión muy veloz y versátil (Dirección de Defensa Aérea, 2019).

El proceso de interceptación se hacía bajo tres fases verificadas por cada miembro de la tripulación, pero en especial por operadores del país anfitrión con un fuerte control del país visitante. La primera fase era la comunicación con la aeronave sospechosa: "debe utilizar una serie de procedimientos reconocidos internacionalmente para hacer contacto visual” con el avión sospechoso. Estos procedimientos, estandarizados por la Organización de Aviación Civil Internacional (OACI), requerían que "el avión de combate volara frente al avión interceptado y moviera sus alas hacia arriba y hacia abajo, bajara su tren de aterrizaje, parpadeara sus luces de aterrizaje y posiblemente emitiera señales manuales" (Helgerson, 2008). El personal de la FAP y CIA se mostraron reacios a comunicarse por radio directamente con el avión sospechoso, pues, si este hubiera sido un avión al servicio del narcotráfico, el temor generalizado de las tripulaciones era ponerlo en sobre aviso y motivar su escapatoria.

La segunda fase, después de agotar todos los posibles medios de comunicación con la aeronave sospechosa era la relacionada con las ráfagas de aviso, entre ellos disparos de advertencia que se hacían al lado del piloto de la aeronave civil. La intención de los disparos era lograr la atención de la aeronave interceptada por lo que tenían en la punta de las balas (cada tres cartuchos) una composición química de fósforo que se encendía al salir disparada formando una línea visual hacia el horizonte y hacia la visión extendida del piloto civil.

Un revelador informe en el proceso de investigación, incluido en el Reporte de Investigación de la CIA (2008), demostró que: 
Los disparos de advertencia consistieron en trazas disparadas por el avión de combate. Algunos oficiales de la CIA declararon que estas trazas se podían ver de noche, pero no durante el día. Sin embargo, otros observaron que la FAP usaba municiones trazadoras viejas que no se encendían o se encendieron solo brevemente, sino que se extinguieron cuando llegó al campo de visión de los pilotos. Los disparos no se pudieron ver en ninguna de las cintas de video de Perú. Además, los pilotos de combate de la FAP describieron estar cegados por el disparo de sus armas por la noche, porque llevaban gafas de visión nocturna. Como resultado, dicen que dispararon solo una de dos ráfagas de unos pocos segundos cada una. La mayoría de los derribos del programa peruano ocurrieron a la luz del día cuando las rondas de rastreo no habrían sido visibles.

\section{El Análisis de los Hechos a partir de las Entrevistas Rea- lizadas a la Tripulación Peruana}

En entrevista con el piloto al mando del A-37 “Tucán”, el interceptor del avión misionero, manifestó que algunos aspectos no se hicieron públicos dentro de la investigación del evento, ni tampoco quedaron plasmadas en el informe de la inspección de la CIA. Uno de ellos, por ejemplo, se relacionaba con la recurrencia al incumplimiento de las normas aeronáuticas peruanas por parte de Donaldson, piloto del hidroavión y que fueron objeto de llamados de atención por parte de la Fuerza Aérea Peruana en anteriores ocasiones (Entrevista semiestructurada a Readhead, septiembre de 2020).

Entre las quejas más comunes entre los pilotos militares era la indisposición de los primeros sobre Donaldson, a quien "no le gustaba encender el transpondedor ni menos diligenciar los planes de vuelo" (Entrevista semiestructurada a piloto peruano, 2020). En el momento del derribo, Donaldson no había diligenciado dicho documento. Tampoco tenía autorización para pasar la noche en Brasil, como lo hizo esa noche en Benjamin Constant, último lugar de permanencia antes del fatídico derribo.

La operación de los aviones interceptores se hacía desde Pucallpa, capital del distrito Callería y provincia del Coronel Portillo en el departamento de Ucayali (Perú). Las condiciones de alojamiento no eran las mejores para los pilotos por temas de seguridad. De hecho, en varias ocasiones miembros de grupos dedicados al tráfico de drogas amenazaron tanto a las tripulaciones como a sus familias, razón por la cual, estos últimos debían dormir con 
chalecos antibala en unos shelter hechos con cartón prensado. De otra parte, las condiciones económicas de Perú no eran las mejores y el sueldo base de un Oficial de grado Capitán era aproximadamente 150 dólares mensuales (Entrevista semiestructurada, septiembre de 2020). En ese sentido, el gobierno estadounidense entregaba una compensación a las tripulaciones involucradas en operaciones de interdicción exitosas. A los pilotos se les entregaban tres mil dólares por derribo, a los copilotos mil dólares y a los demás miembros 500 dólares a cada uno. También eran incentivados con felicitaciones escritas por parte de los miembros de la CIA y DEA (Entrevista semiestructurada a Readhead, septiembre de 2020).

Otra de las observaciones, expuestas por las tripulaciones peruanas se enfocaba en el control cerrado por parte de las tripulaciones estadounidenses. El día del derribo, según como lo asegura el piloto del Tucán, hubo en el área tres aeronaves norteamericanas: el AEW (Awacs), un P3 (ORIÓN) y el C-550 (Citation) [2020]. En este último iba a bordo el oficial de Defensa Aérea de la Fuerza Aérea del Perú encargado de dar trámite a las ordenes por parte de las autoridades locales en el proceso para uso de las armas. Para el caso específico, según Redhead, las tripulaciones peruanas de Defensa Aérea tenían un buen nivel de inglés por lo que su comunicación, por lo regular, era fluida con los estadounidenses; no obstante, el tripulante de ese momento no dominaba bien el idioma inglés (Entrevista semiestructurada, septiembre de 2020).

El resto de la tripulación, tanto los pilotos como el encargado de manejar el radar, cámara infrarroja y sistema de información geográfica eran responsabilidad exclusivamente del funcionario estadounidense y no de los peruanos. Asimismo, las comunicaciones en el momento de la interceptación se realizaban desde el C-550 (Citation). Los pilotos de los aviones interceptores no hablaban directamente con la aeronave en persecución, de tal manera que, todos los mensajes de advertencia y los llamados por las distintas frecuencias debían ser realizadas por el Oficial de Defensa Aérea del Perú a bordo de la plataforma estadounidense en el idioma de la región -español- y en inglés. Al final, el principal error fue el idiomático, pero no el único.

A pesar de haber transcurrido 20 años de estos eventos, es muy poca la información de acceso público disponible, ni las comunicaciones o demás elementos que comprometían a los miembros de esta, se han podido conocer al detalle. Sin embargo, para desarrollar este artículo se tuvo comunicación con uno de los oficiales de la FAP que estuvieron vinculados en los hechos descritos. 
Según Redhead (Entrevista semiestructurada, septiembre de 2020) "el video del derribo, el único encontrado en Youtube, tiene como finalidad inculpar únicamente al gobierno peruano, desconociendo todo el procedimiento realizado por las tripulaciones de ambos países". Se desconocen las motivaciones de la publicación del video, pero lo primero observado durante este procedimiento es negligencia por parte de las tripulaciones involucradas. No obstante, los hechos documentados van en otra vía, habría que estudiar cuál es la responsabilidad de los diseñadores del programa que incluyeron incentivos económicos a los pilotos para que favorecieran el uso de la fuerza.

Llama la atención que este uso de la Fuerza en el marco de un Programa de cooperación bilateral tuviera lugar solo en Perú. Por el contrario, hasta la fecha del suceso, nunca había tenido ámbito de aplicación en espacio aéreo de los Estados Unidos, condiciones que cambiaron posteriormente tras los sucesos del 9/11 (Griffin, 2005).

El derribo del avión de misioneros es el resultado de acuerdos entre dos Estados por el interés común de acabar con el flagelo del tráfico de estupefacientes. Hasta esta parte la intención es clara y loable, pero la configuración del acuerdo se realiza a partir de las dinámicas de poder de cada estado, dejando a los Estados Unidos en una posición de ventaja frente a Perú. Mientras a los estadounidenses involucrados en esta operación no se les vinculó legalmente por gozar de inmunidad diplomática; la tripulación de la FAP fue vinculada en el proceso judicial de manera individual, con la correspondiente responsabilidad económica dentro del proceso incluyendo los derechos pecuniarios de los abogados (Entrevista semiestructurada a Readhead, septiembre de 2020).

Cabe destacar que, en 1992, en el marco del ABD los Estados Unidos y Perú tuvieron un incidente cuando una tripulación de la FAP aplicó el uso de la fuerza contra una aeronave tipo C-130 Hércules de la Fuerza Aérea de los Estados Unidos. En ese momento, las tripulaciones peruanas a bordo de dos aviones SU-22 interceptaron a la norteamericana; pero, según entrevista con el piloto, no se observaba identificación alguna. La aeronave interceptada estaba pintada con un camuflaje de color café y durante la inspección visual las tripulaciones de los dos aviones de fabricación rusa no encontraron ninguna información que pudiera haber advertido sobre la afiliación de esta aeronave. Sumado a lo anterior, el avión tipo Hércules nunca acató las señales de los interceptores peruanos y al contrario buscaron elevarse más, alcanzando 18.500 pies sobre el terreno, y empezaron a alejarse del mar territorial. 
De acuerdo con el piloto interceptor, entrevistado para este artículo (2020) y hoy Mayor General en retiro de la Fuerza Aérea Peruana, la aeronave tomó "rumbo de salida hacia el mar" esperando salir del espacio aéreo nacional. En el proceso de uso del armamento contra la aeronave evasora un tripulante de los 14 a bordo de la aeronave, desconocida hasta ese momento, Joseph Bead Jr, fue expelido de la aeronave cuando los impactos de tiro calibre punto 30 abrieron un orificio suficientemente grande que, con la fuerza de la despresurización rápida, no dio tiempo a ningún tripulante de asegurarse dentro de la aeronave y, por tanto, este cayó al vacío.

El incidente causó la suspensión temporal del Programa de Interdicción aérea entre ambas naciones y una marcada indisposición del gobierno estadounidense hacia sus homólogos peruanos, entre otras, por el reconocimiento público llevado a cabo por el Presidente Fujimori a sus pilotos al haber "defendido la soberanía nacional", como lo haría cualquier nación o como lo pudo haber hecho Colombia en 2013 durante la interceptación del Tupolev TU-160, cuando este ingresó a espacio aéreo nacional sin autorización, quien sería interceptado y obligado a abandonar el territorio por aviones Kfir (Mezú, 2019).

En el caso del derribo del avión con los misioneros a bordo no hubo reconocimiento alguno, aunque la alegría de las tripulaciones combinadas (Estados Unidos y Perú) fue temporal, no hubo ni reconocimiento, ni mucho menos pago de la denominada prima por derribos. Solo se suspendió el programa de interdicción y ambos países fueron muy reservados con el manejo de la información hacia los medios de comunicación.

El informe final realizado tanto por la Fuerza Aérea Peruana, por un lado, y el emitido por la CIA, defendía las posturas políticas de cada uno de los países involucrados y trataba de inculpar a sus pares. Sin embargo, con la publicación del video editado se observaría una culpabilidad de la tripulación peruana, pero esa sería tan solo una parte de la historia. Allí no se hablaba de los más de 100 derribos realizados entre las dos naciones, tampoco de la recurrencia en el desacato de las instrucciones y normas de vuelo del avión derribado y la sospecha por parte de la "Fuerza Aérea Peruana sobre el posible trasiego de sustancias psicoactivas realizadas en ocasiones por el señor Donaldson en su hidroavión" (Entrevista semiestructurada a Readhead, septiembre de 2020).

En la investigación se determinó que, según el registro fílmico, la posición del avión interceptor evitó que el piloto de la aeronave sospechosa lo 
viera. El procedimiento requería que el avión interceptor volara adelante y a la izquierda del sospechoso. En este caso y en casi todas las intermediaciones realizadas por la FAP se observó, según la investigación, a los aviones caza peruanos por detrás del objetivo.

Agotada esa fase y luego de repetir los intentos de comunicación con la aeronave declarada como hostil por frecuencias de radio del sector y, según las reglas aeronáuticas de cada país, la fase final sería el derribo de la aeronave infractora. Revisando el informe de lo ocurrido con el avión de misioneros, fueron pocos minutos los necesarios para derribar erróneamente dicha aeronave (menos de 10 minutos).

Los aviones rastreadores o trackers estaban equipados para hacer grabaciones de los eventos y procedimientos en vuelo con cámaras de video, y cada interceptación era grabada. El personal de la CIA que supervisaba las intercepciones debía usar las cintas de video para verificar la exactitud de las declaraciones sobre la conducta de la intercepción e informar cualquier irregularidad a sus jefes. Si la revisión de la cinta de video no corroboraba las declaraciones escritas hechas en los informes el personal de la CIA debía plantear las discrepancias con sus superiores. Por otro lado, la FAP no pudo verificar eficientemente los planes de vuelo que existían.

Los errores de la tripulación mixta de peruanos y estadounidenses que concluyeron con el derribo del OB-1408 generaron un deterioro en la relación entre los dos países. Decir que lo ocurrido con la familia de misioneros fue un mal necesario, es irrespetar la memoria de las personas fallecidas; pero en la cadena de errores acontecida solo un derribo de este tipo permitió la atención de quien subvencionaba un programa diseñado a la ligera con una visión limitada, en especial, con relación al riesgo sobre la población peruana, ya que, ningún ciudadano estadounidense corría peligro y los derribos por ser en suelo peruano nunca arriesgarían la vida de estadounidenses. Todo fue un error, y ese derribo generó presiones en los Estados Unidos que motivaron cambios para garantizar ante todo la protección de la vida, incluso la de aquellos sobre los que habría sospecha de estar a bordo de un avión ilegal al servicio del narcotráfico.

A partir de la suspensión de esta estrategia en 2001, tanto en Colombia como en Perú se rediseñó el programa; trabajo y validación que transcurrió por espacio de dos años, dando como resultado un nuevo programa llamado Air Bridge Denial (ABD) que iniciaría finalmente en 2003, bajo la tutela del Departamento de Estado de los Estados Unidos, la Fuerza Aérea de los Estados 
Unidos y las cancillerías de Perú y Colombia, así como los ministerios de defensa y las propias fuerzas aéreas (ver capítulo dos). Este programa formulado e implementado bajo nuevas condiciones sobre la lucha contra las drogas, obligó a una estrategia de comunicaciones masiva, con el fin de advertir sobre nuevos procedimientos y prohibiciones, fue dirigida hacia la comunidad aeronáutica y, en especial, hacia aquellos pilotos de la aviación civil, que volaran sobre espacio aéreo colombiano.

El fortalecimiento de la protección de los derechos humanos de los supuestos traficantes aéreos (ver capítulo dos) fue uno de los aspectos de mayor revisión, en las fases y medidas previas, antes de proceder al uso de la fuerza, así como la administración y control de riesgos relacionados que pudieran cometer las partes interesadas dentro de la operación, desde la educación impartida en las escuelas de aviación, en los cursos recurrentes de los pilotos, así como el establecimientos de zonas aéreas de identificación, con una especial sujeción a plan de vuelo y reglas de vuelo por parte de los operadores de aviones civiles. Con presupuesto autorizado por el Congreso de los Estados Unidos de 50 millones de dólares, se dedicaron esfuerzos para mejorar los equipos de las Fuerzas Aéreas de Perú y Colombia, al compartir espacios comunes de frontera sobre la región del Amazonas (Ministerio de Defensa Nacional, 2003). Posteriormente y dentro del segundo capítulo de este libro se ilustrarán las medidas y controles establecidos dentro del $\mathrm{ABD}$.

\section{Narcotráfico, Criminalidad y la Necesidad de Cambios Institucionales}

La lucha contra el tráfico ilegal desde lo aéreo está interconectada a los focos delincuenciales causados por las dinámicas de la siembra de coca en los lugares más apartados de Colombia. Los cuales, además, cuentan con dos ventajas competitivas: I) las condiciones climáticas del país que favorecen la producción y II) la ubicación geoestratégica de Colombia que permite vía terrestre, marítima o aérea; enviar el producto hacia los mercados en Norteamérica, Europa o incluso Asia. Como se mencionó con anterioridad, a finales de la década de 1990 y comienzos del nuevo siglo el negocio de las drogas migró casi que por completo desde Perú, otrora productor de pasta de coca, a Colombia, el intermediario de la pasta de coca peruana. 
La criminalidad aupada en los grandes réditos que da el narcotráfico ha servido como motor para la evolución de este flagelo. La aviación, por ejemplo, ha permitido otorgarles a los grandes capos del narcotráfico una especie de don de ubicuidad. Su rapidez en el trasporte y el poder recorrer extensas distancias en poco tiempo hizo que ésta se volviera un medio de transporte sugestivo. Sumado a lo anterior, la geografía de los países andinos requiere franquear esos nudos montańosos por el aire y, como resultado, la eficiencia del transporte aéreo permitió que toda la logística legal de la aviación sirviera para montar sobre sus hombros la ilegalidad del comercio de las drogas. En la medida en que la aviación iba evolucionando, sin quererlo y tal vez sin saberlo, las oportunidades para el tráfico de las drogas se abrían hacia el exterior.

El 29 de abril de 1948 se realizó la reunión de la OACI, en su sede en Canadá, y se definió un nuevo código de tránsito aéreo internacional. Las nuevas medidas obligaban a los países a mejorar sus condiciones de seguridad e infraestructura aeroportuaria. En tal sentido, mejores aeropuertos serían necesarios, pero también el control de los cielos, un poco descuidados al interior del país. La Fuerza Aérea Colombiana vería la necesidad de mejorar no solo las pistas sino también la flota aérea. Para 1949 el gobierno nacional le compra a los EE. UU. 22 aeronaves por un valor de 182 mil dólares de la época. Un año después el mayor Eduardo Escandón, director de la Aeronáutica Civil, anunció a la opinión pública la intención del control de las comunicaciones aéreas del país por parte de esta entidad. Para 1951 el estado colombiano y el estadounidense anuncian el diseńo de un nuevo convenio relacionado con nuevas políticas asociadas a la administración del espacio aéreo.

La aviación durante la década de 1950 mejoró, en parte gracias a un trabajo de investigación llevado a cabo por el, en su momento, general Gustavo Rojas Pinilla, trabajo de investigación realizado durante la década anterior para optar al ascenso a coronel (Manrique, 2005). En su documento, se enfatizaba en la necesidad de la construcción de algunos aeropuertos en las principales ciudades del país. En 1955, durante la presidencia de Gustavo Rojas Pinilla, el aeropuerto de El Dorado inicia su construcción. En esta época, más de una docena de nuevos aeropuertos se construyen en el país.

Con una infraestructura naciente en términos de aviación, las ventajas de la inmediatez y semi-ubicuidad que genera ésta en un territorio manejado desde el centro y con deteriorados medios de transporte, la aviación toma vuelo y con ella algunas modalidades de delincuencia, entre ellas el 
contrabando aéreo. El primer decomiso de marihuana lo registra El Tiempo en 1963. El cargamento, que incluía no solo marihuana sino también armas largas y cortas, se incautó en Cúcuta y ascendía a un valor de 300 mil dólares. En 1968, según este diario, a finales del año dos periodistas estadounidenses son capturados en el aeropuerto El Dorado con "un empaque de marihuana" entre sus maletas de viaje. En diciembre de ese mismo año, un avión de la empresa Aerocóndor que cubría la ruta Bogotá-Miami a su llegada a EE. UU. se le decomisan alrededor de un alijo de marihuana avaluado en su momento en 75 mil dólares. Según los registros de fuentes primarias extraídos principalmente de este diario de circulación nacional, a partir de 1969 hay un boom en las noticias relacionadas con el tráfico de drogas por vía aérea y en vuelos comerciales. El aeropuerto El Dorado (Bogotá) se convierte en el centro de atención por parte de unidades del extinto Departamento Administrativo de Seguridad (DAS). Se puede decir que hay una narcotización en las noticias y los titulares de prensa que con frecuencia empiezan a registrar grandes cargamentos de droga incautados.

En la figura 1.1 se puede observar detalladamente cómo se da la evolución del tráfico de droga. Inicialmente, como se reporta en los archivos de prensa consultados, los grandes cargamentos incautados eran de marihuana y heroína. Con el tiempo se registran menos incautaciones de los dos anteriores alucinógenos y una gran prominencia de la cocaína que, al final, termina siendo el producto "estrella" de los narcotraficantes colombianos y el "producto de exportación reina” desde finales de la década de 1980 en adelante. Así como la prensa crece en titulares, entidades como la Fuerza Aérea Colombiana empiezan a modernizar su flota de cara en parte al crecimiento en las acciones del narcotráfico (ver capítulo dos). En principio, en la década de 1960 se observa un tráfico ilegal aupado en aviones comerciales; pero, con el tiempo entre los años ochenta y noventa aparecen aeronaves pequeñas usadas para el trasporte ilícito de cocaína. Entonces, para luchar contra este nuevo enemigo se necesitaría de una modernización en la flota aérea de la FAC. A partir de 1970, con el anuncio de su comandante, la FAC empieza a modernizar su flota y es así como llegan no solo aviones para soportar un transporte presidencial más seguro y cómodo, sino también, aviones supersónicos para salvaguardar las fronteras y proteger los cielos. En esa medida, a finales de 1980 llegan los primeros radares militares al país para introducir un nuevo concepto a la doctrina militar relacionada con la defensa aérea, compuesta por radares en 
tierra, aviones de combate y en el futuro aviones de adquisición tipo tracker muy similares a los usados por la CIA en los programas de supresión al tráfico ilegal en Perú y Colombia.

Con la experiencia acumulada durante finales de la década de 1980, los sucesos de Perú y la reingeniería a inicios de 2003, la Fuerza Aérea Colombiana (FAC) ha logrado luchar contra un enemigo a veces invisible, con mucho dinero y capacidad de corrupción (ver capítulo dos). Desde el inicio del aumento del tráfico ilegal se ha observado la intención de los delincuentes de penetrar estas instituciones militares comprando funcionarios involucrados en la interdicción aérea. La FAC debió aumentar los niveles de reserva, así como revisar minuciosamente los ingresos de sus funcionarios. La estrategia, al final resultó en una transformación institucional dispuesta a afrontar los medios y formas del narcotráfico, así como el cambio en los procedimientos para combatir este flagelo, se supeditaron cada vez más al crecimiento de estrategias y aumento del comercio de cocaína entre el sur y el norte. Al final, las capacidades o ventajas competitivas provistas por el clima y la ubicación estratégica de Colombia han permitido un crecimiento de un negocio ilegal que cada día permea más la sociedad colombiana.

\section{Figura 1.1}

Infografía de la evolución del tráfico aéreo ilegal y la respuesta institucional a partir de 1960 


\section{PERIÓDICO \\ EL TIEMPO \\ 1948-1994}
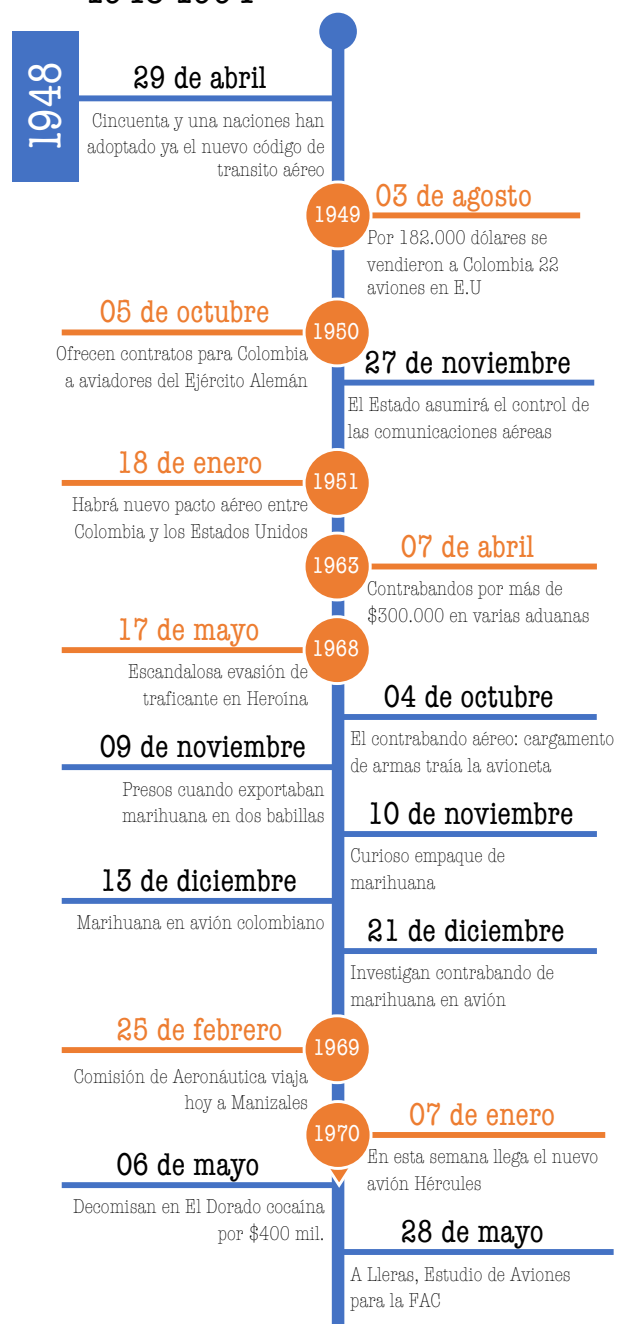

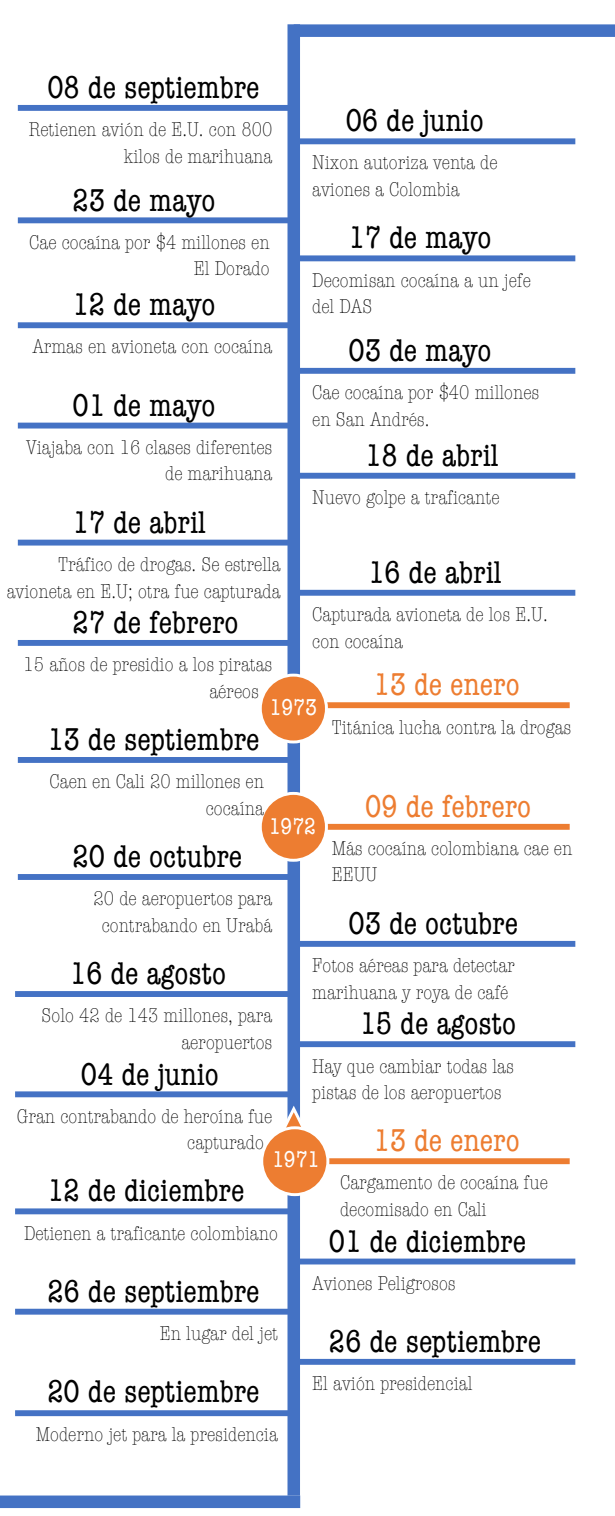

(c) Rodrigo Mezú Mina 2020 


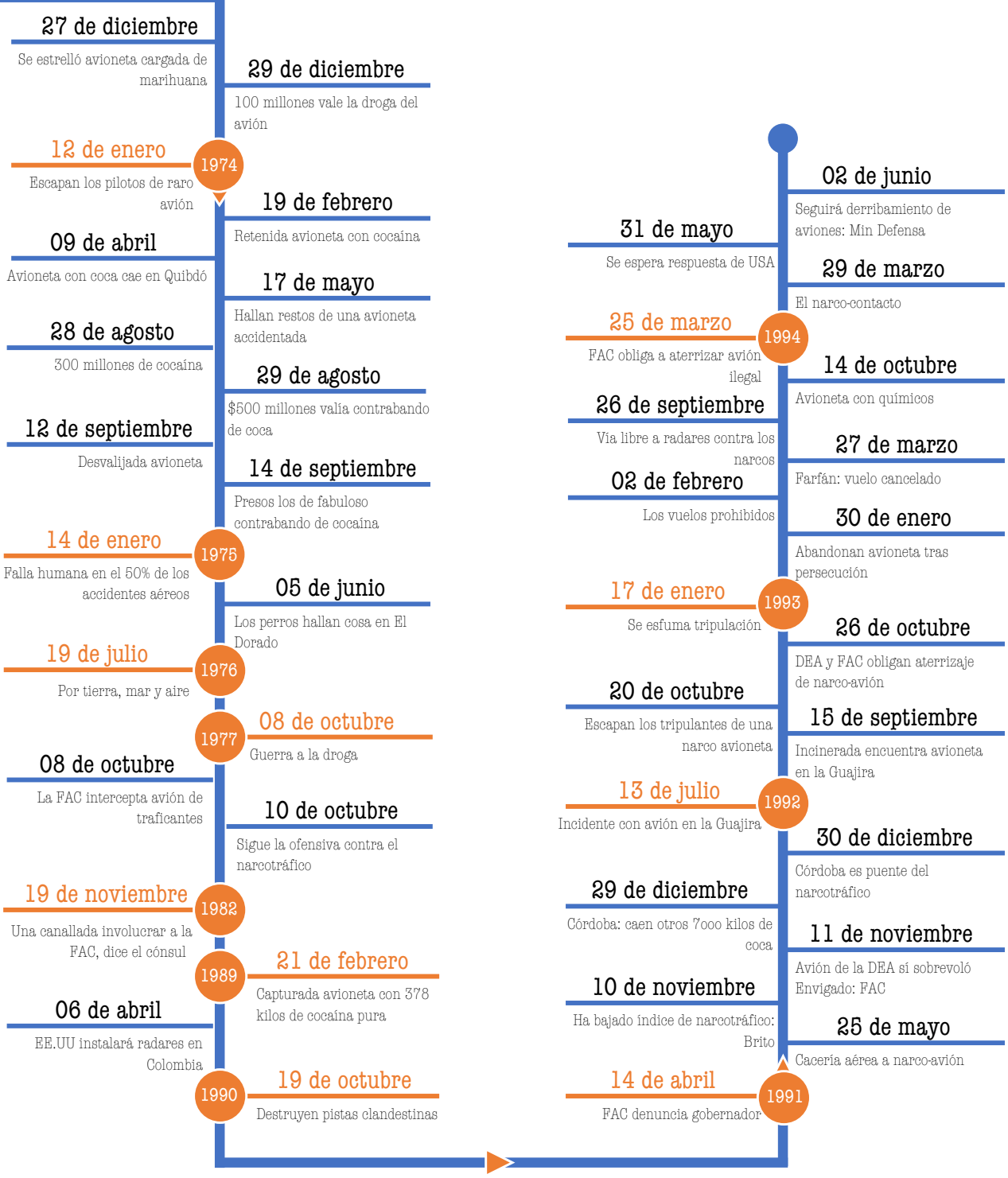

(c) Rodrigo Mezú Mina 2020 


\section{PERIÓDICO \\ EL TIEMPO \\ 1994-2001}

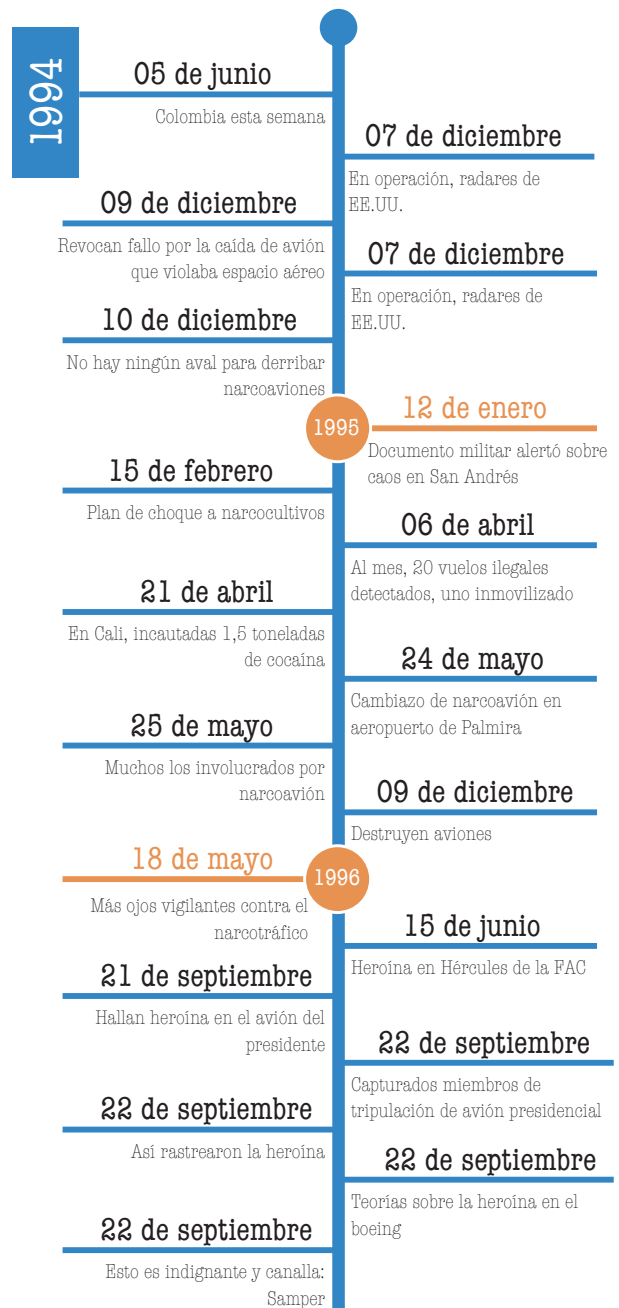

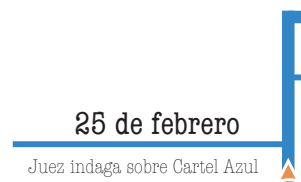

06 de noviembre

Condena por heroina en avión. presidencial

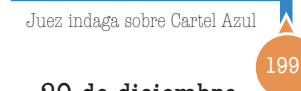

21 de febrero

\begin{tabular}{c}
29 de diciembre \\
\hline Violencia y corrupción \\
12 de octubre \\
\hline En Colombia si hay justicia: \\
General Gil
\end{tabular}

Samper a declarar por caso de heroina, en avión 16 de diciembre

Dictadura de los baches

11 de octubre

El anónimo que en el 93 salpicó a 26 de la $F A C$

\section{3 de octubre}

MinDefensa remitió anónimo a fiscalía,

01 de octubre
Relevo en comandancia de la
base del Catam

29 de septiembre

Colombia esta semana

28 de septiembre

La DEA no participó en inspección

\section{5 de septiembre}

Mantenimiento del Boeing terminó en la tarde del vierne

24 de septiembre
Es exagerado creer que hay
narcos en FAC: Serpa-

\section{3 de septiembre}

Hasta, la mafia se ha robado aviones

22 de septiembre
12 de octubre

Auto de detención a 3 técnicos de Catam

08 de octubre

Militares involucrados en narcotráfico no pueden alegar fuero 02 de octubre Suspenden miembros de la FAC 29 de septiembre Los episodios oscuros en la base del Catam

29 de septiembre

FAC niega amenazas

26 de septiembre

Tres procesos a miembros de FAC por narcotráfico

24 de septiembre

Más de 30 sospechosos por heroina en el Boeing 1201

\section{3 de septiembre}

Este difícil suceso provino del narcotráfico: FAC

23 de septiembre
Investigan itinerario del boeing 


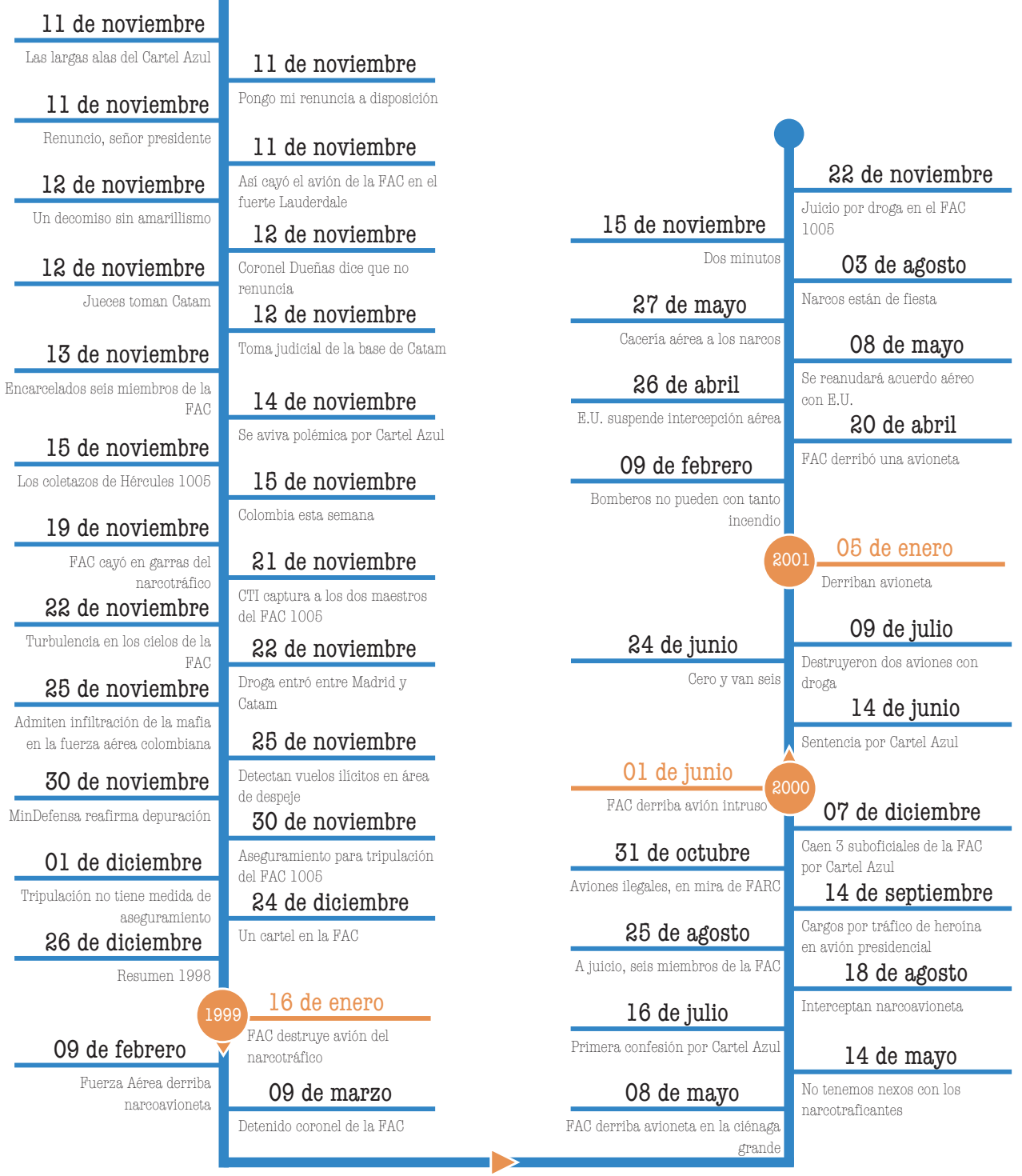




\section{PERIÓDICO \\ EL TIEMPO \\ 2002-2012}
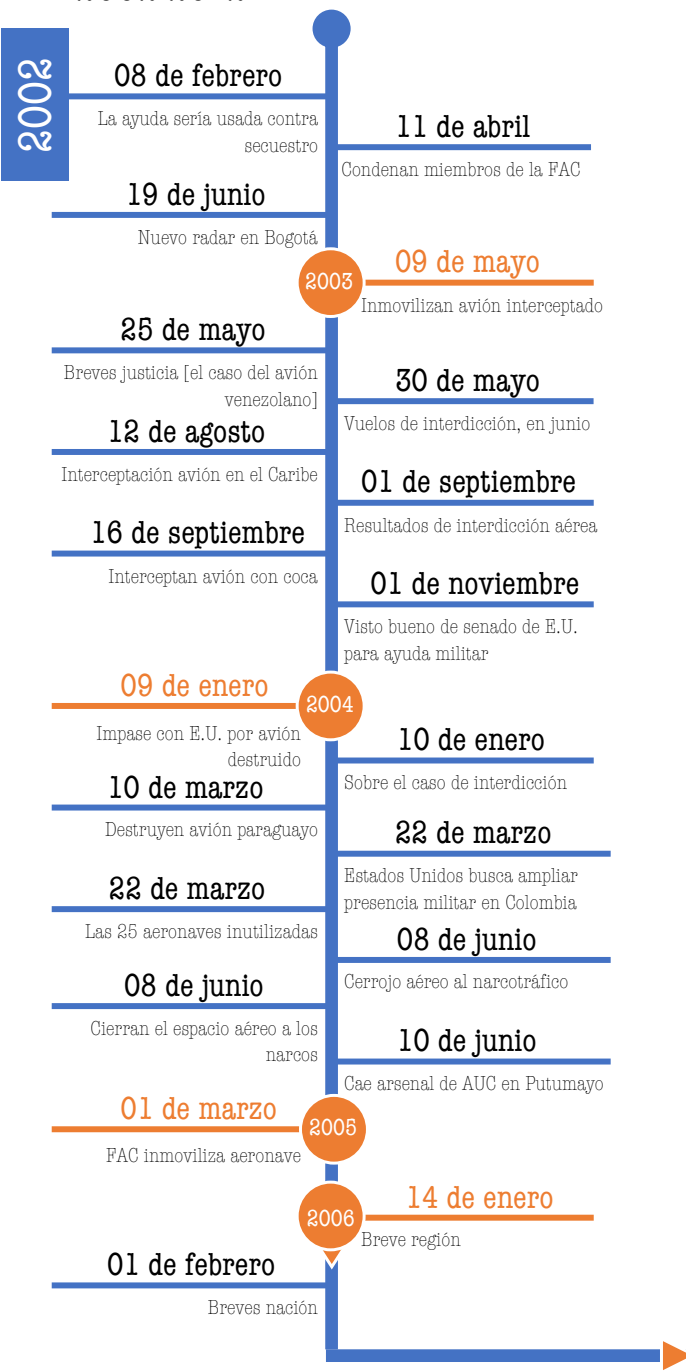

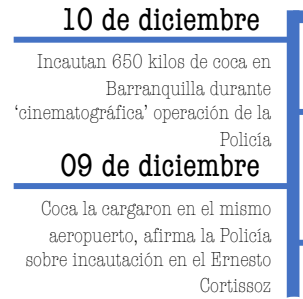

09 de diciembre

Decomisan 650 kilos de cocaína, en el aeropuerto Emesto Cortissoz de Barranquilla

\section{7 de agosto}

n caja de doble fondo la Policía descubre casi cinco kilos de cocaín 10 de marzo
Cae jefe de cartel de La Guajira

08 de noviembre
Matecaña, la. Policía incauta más de siete kilos de cocaína

\section{Z0 de agosto
Caen con coca ex seleccionados}

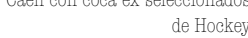

\section{8 de agosto}

Italiano llevaba cocaína impregnada en la ropa

\section{1 de julio}

Policía incautó cocaína en el aeropuerto EI Edén, de Armenia. 09 de marzo

Casi un kilo de cocaína y 100 papeletas de heroína fueron incautados en operativos de la

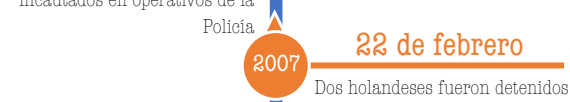

\section{0 de diciembre \\ Colombia extraditó a Estados Unidos a 19 personas, entre ellas un mayor de la Policía 30 de agosto}

2.570 pastillas de éxtasis fueron incautadas en el aeropuerto $\mathrm{E}$ 14 de julio Dorado

Policía detectó cocaína dentro de un busto del escritor Miguel de Cervantes Saavedr

\section{7 de noviembre}

Fiscalía investiga si avión que cayó con 3,7 toneladas de coca en

México sirvió a DEA

\section{2 de octubre}

En Aeropuerto Matecaña de Pereir la Policía incauta casi cuatro kilos de cocaina

19 de agosto

Con coca cayeron dos ex integrantes del equipo nacional de hockey

\section{4 de agosto}

Noticias breves de Justicia

\section{4 de mayo}

Incautan 30 kilos de cocaina en el aeropuerto Eldorado

os holandeses fueron detenido en el aeropuerto con cargament de coca

\section{4 de septiembre}

Autoridades incautaron carca de media tonelada de cocaína en Bogotá

\section{4 de agosto}

Gobiemo anuncia que coca de parques se erradicará mediante fumigiación aérea 


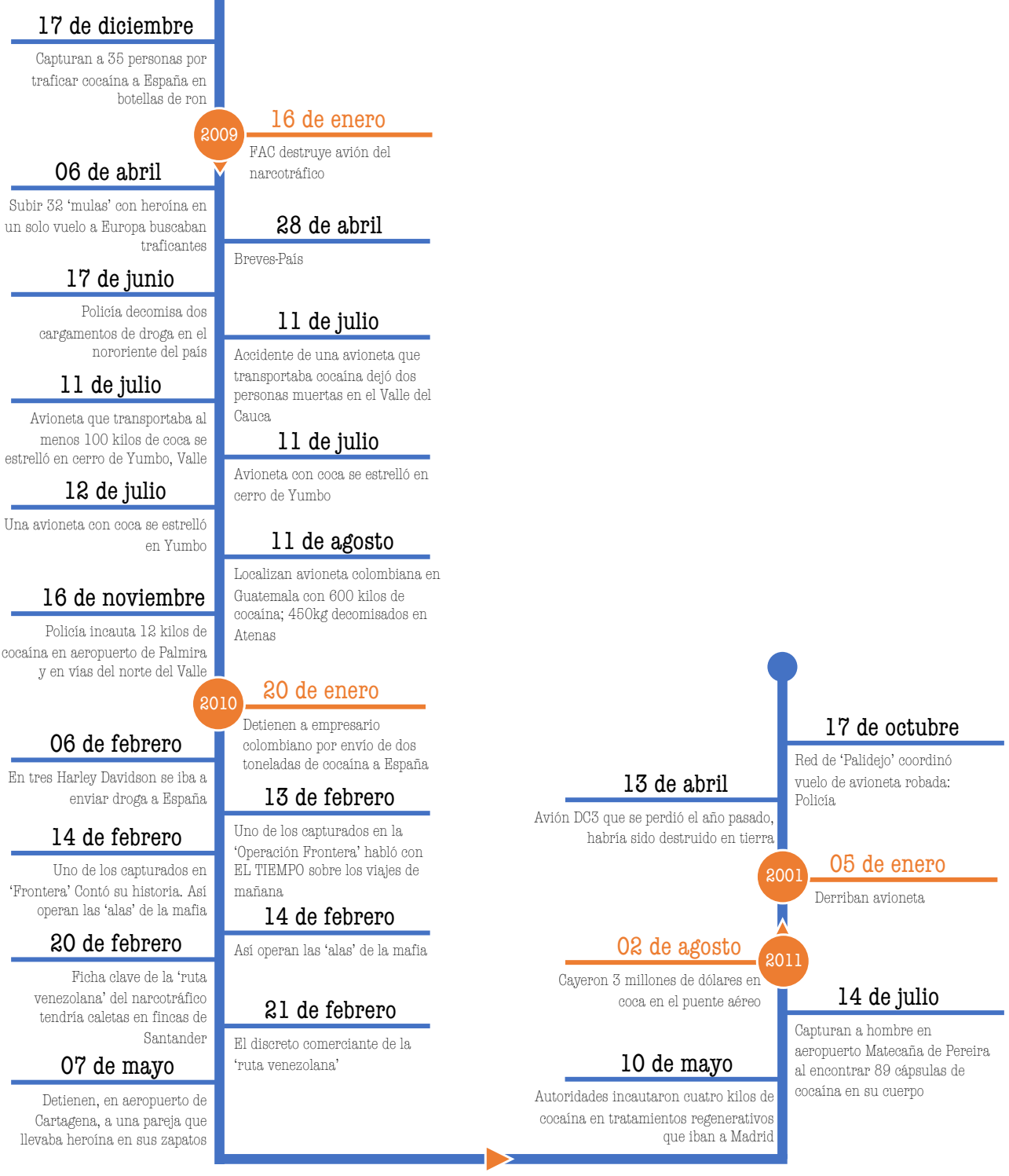




\section{Narcotráfico, Debilidad Estatal y Retos de Cara a Proce- sos de Reajuste Institucional}

Francisco E. Thoumi en su artículo titulado Ventajas competitivas ilegales, el desarrollo de la industria de drogas ilegales y el fracaso de las politicas contra las drogas en Afganistán y Colombia, considera que, el hecho de que ambos países sean dominantes en el tráfico ilegal del opio y la cocaína, respectivamente, explica por qué estos países presentan ciertas características que les han permitido tener cierta ventaja competitiva, sumado a la debilidad en los controles que estos Estados presentan (2005). En su opinión:

La actividad económica ilegal requiere, además de rentabilidad, la existen-
cia de controles débiles tanto estatales como sociales al comportamiento
individual. Esto es, una sociedad en la que las leyes del Estado se pueden
evadir con facilidad y en las que las normas sociales toleren tal evasión. (2005, p. 31)

Por su parte, en el documento Cocaine's long march north, 1900-2010, Paul Gootenberg (2012) expone los problemas y contradicciones que ha generado en la región latinoamericana, principalmente en la zona andina y en México, la política antidrogas, prohibitiva y punitiva, promovida desde los Estados Unidos de América. Desde una perspectiva histórica e institucional, Gootenberg realiza un recuento detallado sobre las transformaciones geopolíticas en la producción y tráfico de cocaína, así como en el incremento en los niveles de violencia que se han generado en los epicentros del tráfico de este alcaloide, como sucedió en Colombia durante las décadas de 1980 y 1990. Para su análisis plantea cuatro etapas históricas que explican dicha evolución resultando en el nacimiento, desarrollo y fortalecimiento del tráfico ilegal de drogas con una fuerte incidencia en Chile y posteriormente la activación de mercados en Bolivia, Colombia y México (2012). Todo el esfuerzo enfocado a satisfacer un mercado naciente que, para mediados de 1980, había alcanzado en tierras estadounidenses 22 millones de consumidores (Gootenberg, 2012, p. 168). El narcotráfico se instalaría en Colombia bajo la incapacidad estatal y la creatividad de nuevos entrepreneurs, llamados popularmente narcos.

En el caso colombiano, desde hace varias décadas, se presentó una simbiosis entre narcotráfico y las guerrillas. Sin embargo, con los atentados del 11 de septiembre de 2001 y la aplicación de la Política de Seguridad Democrática (ver capítulo dos), se unificaron las dos guerras: la anti insurgen- 
te (que se transformó en antiterrorista) y aquella que se desarrolla contra el narcotráfico. Como resultado de esta unificación, se generó una reducción en los niveles de violencia, aunque se mantiene el negocio de las drogas. En el contexto de esta guerra, "la guerrilla se transformó en el enemigo principal y se negoció la desmovilización de bandas paramilitares ligadas al narcotráfico (la pax uribista)" (Palacios \& Serrano, 2010, p. 107).

Richard Snyder y Angélica Durán, en su análisis del aumento de la criminalidad en México, señalan que en el caso de ese país:

La red de protección patrocinada por el Estado se formó en la década de 1940 y duró hasta finales de 1980, lo que resultó en bajos niveles de violencia relacionada con el tráfico de drogas. La ruptura de la red de protección, debido a un aumento en la competencia política, las reformas contra la corrupción, y los nuevos participantes en el mercado ilícito, en conjunto, alteraron los horizontes temporales de los funcionarios estatales y alteraron la geografía del cumplimiento, lo que dio lugar a un fuerte aumento de la violencia. (2009, p. 87)

Es decir, la transición democrática que vivió ese país generó una serie de reacomodos de instituciones informales como las redes de protección que se habían tejido previamente. Este reacomodo se generó como resultado de cuestiones como el aumento en la pluralidad y la fragmentación políticas que esto conllevó. Además, al romperse esas redes de protección, también se generaron cambios en las estructuras de criminalidad y en las prácticas organizativas que habían generado los cárteles mexicanos como parte de una especie de path dependence, por lo que los cambios institucionales, tanto formales como informales, que se generaron derivaron en un aumento en las disputas entre los cárteles y en la fragmentación de estos.

Estudiosos del narcotráfico como Bruce Bagley (2009) y Eduardo Guerrero (2014) consideran que la fragmentación de las organizaciones mayores expande la violencia espacialmente -el denominado efecto cucaracha señalado por Bagley-, algo que se hizo evidente en el caso colombiano cuando se fragmentaron los cárteles de Medellín y Cali y se generaron nuevas organizaciones criminales. Junto con la fragmentación de los cárteles crece la delincuencia y se diversifican las actividades criminales, sobre todo por parte de las organizaciones con menores capacidades, hacia acciones ilegales como la extorsión, el secuestro, el tráfico de personas, el narcomenudeo, entre otras. 
La variable institucional resulta esencial a la hora de analizar las causas y las consecuencias de fenómenos relacionados con las actividades criminales. Cuestiones como la debilidad institucional para la aplicación del estado de derecho, de la procuración de la justicia y la corrupción generan incentivos para el aprovechamiento de esas debilidades por parte de las organizaciones criminales y, en casos extremos, para la captura del Estado por parte de actores e intereses contrarios a la legalidad. Esa misma variable institucional es la que permitió durante finales de la década de 1990 y comienzo del siglo XXI que las instituciones encargadas de luchar contra el narcotráfico, en todas sus acepciones empezaran perdiendo la batalla. Mientras los grupos de narcotraficantes se aliaban con los grupos guerrilleros y la delincuencia común en el afán de asegurar el negocio del tráfico de drogas, algunas instituciones del Estado eran más permeadas por el mismo narcotráfico. No era necesario diseñar nuevos programas de interdicción aérea, marítima y terrestre, sino también, se requería de funcionarios "inmaculados", apasionados por su labor de "buenos policías" y, sobre todo, resistentes a la corrupción.

En opinión de Eduardo Buscaglia (2013):

Las delincuencias organizadas que se encuentran ante Estados fuertes, con mecanismos de control judicial patrimonial constituidos y funcionales, son empresas criminales que nunca hacen frente al Estado de igual a igual con acciones de violencia extrema, sino de manera silenciosa, se dedican principalmente a delitos económicos de menor impacto. Sin embargo, cuando los Estados son débiles, las empresas criminales regionales y transnacionales compiten salvajemente, con violencia, para ocupar vacíos de Estado, absorbiendo fragmentos completos de territorio y de andamiaje institucional, para después consolidar sus mercados ilegales en delitos organizados mucho más graves. (pp. 25-26)

Un ejemplo del aprovechamiento de los vacíos dejados por el Estado cuando este se debilita, se presenta con el caso de la transición de la extinta Unión de Repúblicas Socialistas Soviéticas (URSS) a la Federación Rusa. El paso de un Estado autoritario a un régimen hibrido (Levitsky \& Way, 2010). $\mathrm{Al}$ respecto Federico Varese (1997), en un artículo titulado The transition to the market an corruption in Post-socialist Russia, plantea que los altos niveles de corrupción, evasión fiscal y criminalidad presentes en la era post Unión Soviética se generaron por factores como la falta de una adecuada definición en los derechos de propiedad, las dificultades para obtener ganancias y la falta 
de garantías de seguridad en la propiedad por parte del Estado. En opinión de Varese (1997), la transición abrupta al libre mercado dejó al Estado ruso sin las capacidades adecuadas para garantizar la certeza jurídica que se requiere para incentivar la inversión. En contraparte, se generaron incentivos perversos como el fraude o las evasiones fiscales promovidas por grupos o coaliciones que mediante prácticas corruptas generaron distorsiones en el mercado $\mathrm{y}$, al mismo tiempo, debilitaron a las instituciones del Estado en beneficio de sus intereses. Además, estas condiciones de debilidad institucional erosionaron la efectividad en el control de la criminalidad que se tuvo durante el régimen socialista y, en cambio, se generó un incremento masivo en las tasas de criminalidad, como resultado de las debilidades institucionales que generaron incentivos para cometer actividades criminales, ya que estas no serían investigadas y mucho menos sancionadas.

De tal forma, Varese (1997) muestra la forma en que la debilidad institucional tiene efectos negativos sobre la capacidad del Estado para ejercer un aspecto central: "el control del uso legítimo de la fuerza", y que estas debilidades y vacíos institucionales generan estímulos para la corrupción, la criminalidad y la captura del Estado por parte de intereses privados o ilegales.

Países con Estados débiles, suelen encontrarse en procesos de transición política en los que no se han desarrollado instituciones eficaces y democráticas (Buscaglia, 2013). Por tanto, la fortaleza de las instituciones estatales y el proceso de dotarlas de capacidades que mejoren su eficacia en la aplicación de controles resulta un aspecto clave para hacer frente a los fenómenos de criminalidad que se presentan. Mientras que el $80 \%$ de las víctimas de los conflictos a principios del siglo pasado eran militares, se estima que el $80 \%$ de las víctimas de aquellos choques contemporáneos son civiles. Esta nueva forma de conflictos es un desafío político más que militar, que involucra la ruptura de la legitimidad y la necesidad de una nueva política cosmopolita para reconstruir las comunidades y sociedades afectadas (Kaldor, 1999).

Los retos al término de los conflictos armados son inmensos. La transición hacia la paz no es fácil. La evidencia sugiere que, en muchos casos, la violencia, delincuencia común y los factores sociales que se creían finalizados al firmar un acuerdo se acabarían (Keen, 2000). Por el contrario, generalmente hay una creciente ola de violencia. Los casos de Sudáfrica, Guatemala, El Salvador y, ahora, Colombia, son ejemplo de aquellos picos de violencia una vez se ha firmado un acuerdo de paz con una organización insurgente. Las respuestas a los retos de la seguridad desde las instituciones son a través de un mayor músculo militar, craso error. Kurtenbach y Rettberg (2019) aseguran 
cuán dañina puede ser esta solución, pues, los presupuestos en defensa terminan reduciendo los destinados a fortalecer el tejido social de una comunidad en reconstrucción (Gates, Jones \& Strand, 2006). No obstante, es difícil afirmar que bajo un incremento en el presupuesto social de una nación en transición, los retos a la seguridad serán resueltos. Los estados requieren comprometerse en una clara rendición de cuentas ante su público y evitar los usos de recursos públicos en intereses privados. A este nivel, todo lo relacionado con políticas públicas se traduce en necesidades presupuestales. Ello incentiva luchas al interior de los gobiernos entre instituciones hermanas desviando el esfuerzo sobre temas comunes y necesarios para hacer frente a los retos de una seguridad humana.

\section{Conclusiones}

La visión de la lucha contra el tráfico de drogas ha sido regida bajo las condiciones impuestas por la interdependencia compleja entre un país rico, como lo es Estados Unidos y otro necesitado, como el caso de Colombia. No es un secreto que el dinero lo ha puesto el gobierno estadounidense y, por lo tanto, la estrategia en la lucha contra las drogas se ha visto influenciada por esta "gran estrella del norte". Inicialmente su preocupación estaba alineada con la protección legal de sus nacionales ante un posible litigio a raíz de un mal procedimiento mientras estaba en marcha el programa de interdicción aérea en Perú. Sin embargo, bajo un procedimiento evitable derribaron a un avión con una familia de estadounidenses, lo cual obligó a cambiar la estrategia en la lucha contra las drogas. Esta estrategia mutó a un programa más respetuoso y garantista a la hora de aplicar la fuerza y, con el tiempo, el único país capaz de mantenerse en el aire con cero incidentes reportados sería Colombia. Y aunque el programa colombiano hoy en día es operado $100 \%$ por la Fuerza Aérea Colombiana, la herencia y el mismo diseño del programa de interdicción fue diseñado por quien poseía el dinero y allí la limitante para evolucionar tecnológicamente dicho programa. Hoy las aeronaves al servicio del narcotráfico poco usan el espacio aéreo colombiano y evitan encontrarse en el aire con la Fuerza Aérea Colombiana; sin embargo, se requiere de mayor desarrollo tecnológico para actualizar la nueva generación de interceptores y, por qué no, reinventar un nuevo programa de interdicción más dinámico y menos reactivo.

La experiencia peruana sirvió para demostrar la capacidad de formación del talento humano como un factor decisivo en la lucha contra el tráfico aéreo 
ilegal. La capacidad para operar bajo un ambiente de presión y usando una segunda lengua ha sido un reto para las tripulaciones encargadas de enfrentar la amenaza del narcotráfico en el aire. Así, este programa ha sido un éxito para la FAC pues le permitió crecer y desarrollarse doctrinariamente gracias a los recursos y entrenamiento derivado de la lucha contra el narcotráfico.

\section{Referencias}

ABC News. (4 de febrero de 2010). Air Force jet shoots down civilian plane [Archivo de vídeo]. Recuperado de https://www.youtube.com/watch?v=vf8oGrqEtsI

Anthony, R. W., Crane, B. D., \& Hanson, S. F. (2000). Deterrence Effects and Peru's Force-Down/Shoot-Down Policy: Lessons Learned for Counter-Cocaine Interdiction Operations. Institute for Defense Analyses IDA (No. IDA-P-3472). Virginia. Recuperado de https://apps.dtic.mil/ dtic/tr/fulltext/u2/a381193.pdf

Bagley, B. (2009). La conexión Colombia-México-Estados Unidos. En R. Benítez, A. Rodríguez, A. Rodríguez-Luna (Ed.), Atlas de la Seguridady la Defensa de México 2009 (pp. 24-32).

Bedoya, M. (2016). La lucha contra las drogas: fracaso de una guerra, comienzo de una nueva política. Drugs and Addictive Behavior (histórico), 1(2), 237-254. doi:https://doi.org/10.21501/24631779.2060

Bureau of International Narcotics and Law Enforcement Affairs [INL]. (2001). Peru Investigation Report: The April 20, 2001 Peruvian Shootdown Accident [en línea]. U.S. Department of State. Washington, DC. Recuperado de https://fas.org/irp/news/2001/08/peru_shootdown.html

Buscaglia, E. (2013). Vacios de poder en México: cómo combatir la delincuencia organizada. Debate.

Clutterbuck, R. (1995). Peru: Cocaine, terrorism and corruption. International Relations, 12(5), 77-92. https://doi.org/10.1177/004711789501200506

CNN. (21 de abril de 2001). Plane shootdown: Drug intercept flights suspended in Peru http://edition.cnn.com/2001/US/04/21/peru.plane.02/

Dirección de Defensa Aérea (2019). 17 Aniversario de la creación de su especialidad y por otra, las 10.000 horas de vuelo del avión SR-560 Citation. Recuperado de https://www.fac.mil.co/la-dirección-de-defensa-aérea-está-de-celebración 
Esquivel, R. (2019). Fuerza Aérea y conflicto en el Caribe colombiano, 1980-2010. Ciencia y Poder Aéreo, 14(2), pp. 122-139. https://doi. org/10.18667/cienciaypoderaereo.637

Felbab-Brown, V. (2005). The Coca Connection: Conflict and Drugs in Colombia and Peru. Journal of Conflict Studies, 25(2), pp. 104-128. Recuperado de https://journals.lib.unb.ca/index.php/JCS/article/view/489

Gagne, D. (13 de enero de 2015). Balance de InSight Crime sobre homicidios en Latinoamérica en 2014. InSight Crime. Recuperado de https:// es.insightcrime.org/noticias/analisis/resumen-insight-crime-sobre-homicidios-en-2014/

Gates, S., Hegre, H., Jones, M. P., \& Strand, H. (2006). Institutional inconsistency and political instability: Polity duration, 1800-2000. American Journal of Political Science, 50(4), pp. 893-908. https://doi.org/10.1111/ j.1540-5907.2006.00222.x

Gootenberg, P. (2012). Cocaine's long march north, 1900-2010. Latin American Politics and Society, 54(1), pp. 159-180. https://doi.org/10.1111/ j.1548-2456.2012.00146.x

Griffin, D. R. (2005). The 9/11 Commission report: Omissions and distortions. Olive Branch Press.

Guerrero, E. (21 de octubre de 2014). Detienen en Lima y Tarapoto a un comandante y 8 suboficiales PNP por tráfico de drogas [en línea]. La República. Recuperado de https://larepublica.pe/politica/828822-detienen-en-lima-y-tarapoto-a-un-comandante-y-8-suboficiales-pnp-por-trafico-de-drogas/

Helgerson, J. L. (2008). Procedures used in narcotics Airbridge Denial Program in Peru, 1995-2001 (No. C05500526). Central Intelligence Agency. Washington DC Office of the Inspector General. Recuperado de https:// fas.org/irp/cia/product/ig-airbridge.pdf

Huskisson, D. C. (2004). The Air Bridge Denial Program and the Shootdown of Civil Aircraft Under International Law [tesis de maestría]. McGill University, Montreal.

Kaldor, M. (1999). New and old wars: Organized violence in a global era. Sandford University Press.

Keen, D. (2000). War and peace: what's the difference? International Peacekeeping, 7(4), pp. 1-22.

Kurtenbach, S., \& Rettberg, A. (Ed). (2019). War economies and post-war crime. Abingdon: Routledge. ThirdWorlds. 
LADB Staff. (24 de octubre de 1997). U.S. Drug Czar Barry Mccaffrey Visits Colombia. Recuperado de https://digitalrepository.unm.edu/notisur/ 12424

Levitsky, S., \& Way, L. A. (2010). Competitive authoritarianism: Hybrid regimes after the Cold War. Cambridge University Press.

Manrique, L. E. (2006). A Parallel Power: Organized Crime in Latin America. Real Instituto Elcano de Estudios Internacionales y Estratégicos, Madrid.

Mezú Mina, R. (2019). La interceptación de los Tupolev: enseñanzas desde la doctrina y la estrategia. Ciencia Y Poder Aéreo, 14(2), 82-95. https://doi. org/10.18667/cienciaypoderaereo.635

Ministerio de Defensa Nacional. (2003). Gobierno explica Convenio de Interdicción con Estados Unidos [nota de prensa]. Recuperado de https://www. fac.mil.co/gobierno-explica-convenio-de-interdicción-con-estados-unidos

Organización de las Naciones Unidas [ONU]. (2018). World Drug Report 2018: opioid crisis, prescription drug abuse expands; cocaine and opium hit record highs. Oficina de las Naciones Unidas contra la Droga y el Delito [UNODC]. Recuperado de https://www.unodc.org/doc/wdr2018/ WDR_2018_Press_ReleaseENG.PDF

Organización Internacional para las Migraciones [OIM]. (2019). Gaceta de Paz del 17 al 23 de abril de 2019. Recuperado de https://repositoryoim. org/bitstream/handle/20.500.11788/2184/116.\%20Gaceta\%20de\%20 Paz\%2017-23\%20Abril\%202019.pdf?sequence=1

Otis, J. (2014). The FARC and Colombia's illegal drug trade. Wilson Center, pp. 1-26. Disponible en https://www.wilsoncenter.org/sites/default/files/ media/documents/publication/Otis_FARCDrugTrade2014.pdf

Palacios, M., \& Serrano, M. (2010). Colombia y México: las violencias del narcotráfico. En Los grandes problemas de México. XV. Seguridad nacional y seguridad interior (pp. 105-154). México D.F.: El Colegio de México.

Pardo, R. (2020). La guerra sin fin. Bogotá: Aguilar

Snyder, R., \& Durán-Martínez, A. (2009). Drugs, violence, and state-sponsored protection rackets in Mexico and Colombia. Colombia Internacional, (70), pp. 61-91. https://doi.org/10.7440/colombiaint70.2009.03

Thoumi, F. (2005). The numbers game: let's all guess the size of the illegal drug industry! Journal of Drug Issues 35(1), pp. 185-200. https://doi. org/10.1177/002204260503500109 
United States General Accounting Office [GAO]. (1994). U.S. Drug Interdiction Issues in Latin America. Recuperado de https://www.gao.gov/ assets/110/105726.pdf

Varese, F. (1997). The Transition to the Market and Corruption in Postsocialist Russia. Political Studies 45(3), pp. 579-596. https://doi. org/10.1111/1467-9248.00097 